\title{
Stock Returns in Mergers and Acquisitions*
}

\author{
Dirk Hackbarth ${ }^{\dagger} \quad$ Erwan Morellec ${ }^{\ddagger}$
}

October 2006

\begin{abstract}
This paper develops a real options framework to analyze the behavior of stock returns in mergers and acquisitions. In this framework, the timing and terms of takeovers are endogenous and result from value-maximizing decisions. The implications of the model for abnormal announcement returns are consistent with the available empirical evidence. In addition, the model generates new predictions regarding the dynamics of firm-level betas for the time period surrounding control transactions. Using a sample of 1086 takeovers of publicly traded US firms between 1985 and 2002, we present new evidence on the dynamics of firm-level betas, which is strongly supportive of the model's predictions.
\end{abstract}

Keywords: takeovers; real options; stock returns; firm-level betas.

JEL Classification Numbers: G13, G14, G31, G34.

\footnotetext{
${ }^{*}$ We especially thank Michael Brennan for many valuable comments on the paper. We also thank Ilan Cooper, Thomas Dangl, Alex Edmans, Armando Gomes, Diego Garcia, Michael Lemmon, Lubos Pastor, Robert Stambaugh (the editor), Neal Stoughton, Ilya Strebulaev, Josef Zechner, Lu Zhang, Alexei Zhdanov, an anonymous referee, and seminar participants at the UBC summer finance conference, the UNC-Duke conference on corporate finance, the 2006 EFA meetings in Zurich, the conference on Asset Returns and Firm Policies at the University of Verona, the University of Vienna, and Washington University in St. Louis for helpful comments. Erwan Morellec acknowledges financial support from the Swiss Finance Institute and from NCCR FINRISK of the Swiss National Science Foundation.

${ }^{\dagger}$ Washington University in St. Louis. E-mail: hackbarth@wustl.edu. Postal: John M. Olin School of Business, Washington University, Campus Box 1133, One Brookings Drive, St. Louis, MO 63130.

${ }^{\ddagger}$ Swiss Finance Institute, University of Lausanne and CEPR. E-mail: erwan.morellec@unil.ch. Postal: Ecole des HEC, University of Lausanne, Rte de Chavannes 33, 1007 Lausanne, Switzerland.
} 


\section{Introduction}

Decisions that affect the scope of the firm are amongst the most important faced by management, and amongst the most studied by academics. Mergers and acquisitions are classic examples of such decisions. While there exists a rich literature that examines why firms should merge or restructure, we still know very little on the asset pricing implications of these major corporate events. This paper develops a model for the dynamics of stock returns in mergers and acquisitions, in which the timing and terms of takeovers are endogenous and result from value-maximizing decisions. The implications of the model for abnormal announcement returns are consistent with the available empirical evidence. In addition, the model generates new predictions regarding the dynamics of firm-level betas for the time period surrounding control transactions. Using a sample of 1086 takeovers of publicly traded US firms between 1985 and 2002, we present new evidence on the behavior of stock returns through the merger episode, which is strongly supportive of the model's predictions.

Control transactions generally create value either by exploiting synergies or by improving efficiency through consolidation and disinvestment. In this paper, we present a theory that encompasses both motives and examine the implications of this theory for stock returns. Specifically, we consider a model in which two public firms can enter a takeover deal. In the takeover, the more inefficient firm sells its assets to the more efficient one and thereby puts its resources to their best use. After the takeover, the merged entity has the possibility either to invest in new assets or to divest some of the acquired assets. Our model therefore emphasizes the role played by efficiency and capital reallocation in the timing and terms of takeovers. ${ }^{1}$ It also contributes to the literature that examines the impact of growth options and disinvestment opportunities on the dynamics of mergers and acquisitions.

In our model, investment decisions share two important characteristics. First, there is uncertainty surrounding their benefits. Second, these decisions are at least partially irreversible. The decision to enter a takeover deal, expand operations, or divest assets can then be regarded as the problem of exercising a real option. One essential difference between the option to enter the takeover deal and the options available to the merged entity after the takeover is that the former involves two firms. This implies that the timing and terms of the takeover are the outcome of an option exercise game in which each firm determines an exercise strategy for its real option, while taking into account

\footnotetext{
${ }^{1}$ As discussed in the paper, this motive for mergers implies that the bidder has a higher Tobin's $q$ than the target. However, it need not imply large differences in market-to-book ratios as the values of the bidding and target firms also reflect the potential benefits associated with the restructuring, which tends to reduce the relative differences in market values.
} 
the other firm's exercise strategy (see also Grenadier, 2002). By contrast, the options to expand or divest represent standard investment decisions that can be made in isolation. Because the takeover surplus depends on the operating options available to the merged entity, the derivation of value-maximizing strategies in the paper proceeds in two steps. The first step determines the exercise strategies for the expansion and contraction options of the merged entity. The second step derives the equilibrium restructuring strategies, taking the optimal expansion and contraction strategies as given.

Following the determination of equilibrium exercise strategies, the implications of the equilibrium for stock returns are analyzed. Two important contributions follow from this analysis. First, we provide a complete characterization of the dynamics of firm-level betas through the merger episode and show that beta changes dramatically in the time period surrounding takeovers. Notably, we demonstrate that depending on the relative risks of the bidding and the target firm before the takeover, the beta of the bidding firm might increase or decrease prior to the takeover. In particular, we show that when the acquiring firm has a higher (lower) pre-announcement beta than its target firm, the risk of the option to enter the takeover deal is higher (lower) than the risk of the underlying assets. As the takeover becomes more likely, the value of the option to merge increases as a percentage of total firm value. Hence the (priced) risk of the acquiring firm increases and so does its beta. Therefore, our model predicts that we should observe a run-up (run-down) in the beta of the bidding firm prior to the takeover when the acquiring firm has a higher (lower) beta than its target.

The second key contribution of this paper relates to the change in beta at the time of the takeover. By exercising their real options, firms change the riskiness of their assets and therefore affect their betas and expected stock returns. Before the merger, shareholders of the bidding firm hold an option to enter the takeover deal. By merging with the target, bidding shareholders exercise their (call) option and change the nature of the firm's assets. It is commonly understood that (call) option exercise should trigger a reduction in beta and expected returns. Our results challenge this intuition. We show that the sign of the change in beta at the time of the takeover depends on the relative risks of the bidding and target firms. As a result, the long-run performance of the merged entity may be lower or higher than the performance of the bidding firm prior to the takeover. We also show that the magnitude of the change in beta at the time of the takeover depends on several characteristics of the deal such as the presence of bidder competition, saymmetric information, or follow-up options.

To test our model, we form a sample of large control transactions based on the Securities Data Company's (SDC) U.S. Mergers \& Acquisitions database. We restrict our attention to publicly traded firms and obtain a sample of 1086 takeovers with announcement dates ranging from January 1, 1985, to June 30, 2002. We first examine 
abnormal announcement period returns for our sample. The data demonstrate the same general patterns that have been documented in the literature. We then turn to the analysis of firm-level betas by estimating monthly betas calculated from daily returns. We follow the high-frequency or "realized beta" approach of Andersen et al. (2005) and find that firm-level betas vary dramatically in the time period surrounding the announcement of a deal. More specifically, our analysis reveals that beta does not exhibit any increase or decrease prior to the takeover and drops only moderately after a merger announcement for the full sample of deals. However, if we split our sample into two subgroups in which acquiring firms have either a higher or a lower pre-announcement beta than their targets, the patterns we find in the beta of acquiring firms are consistent with the model's predictions. Beta first increases slowly and then declines upon announcement for the subsample of deals in which the beta of the bidder exceeds the beta of the target. Beta first declines slowly and then rises upon announcement for the other subsample of deals.

This paper continues a line of research using real options models to analyze mergers and acquisitions. Margrabe (1978) is the first to model takeovers as exchange options. In his model, takeovers involve a zero-sum game and timing is exogenous. Lambrecht (2004) and Morellec and Zhdanov (2005) study takeovers using a real options setting with endogenous timing. Magsiri, Mello, and Ruckes (2005) study a firm's decision to grow internally or externally by making an acquisition. Finally, Morellec (2004) and Lambrecht and Myers $(2005,2006)$ examine the relation between manager-shareholder conflicts and the external market for corporate control. This paper extends the existing literature in two important dimensions. First, we model the operating options available to the merged entity after the takeover. This allows us to make a clear distinction between mergers that create growth opportunities and mergers that lead to divestitures, spin-offs, or carve-outs. Second, and more importantly, our model also adds to the literature by characterizing explicitly the dynamic behavior of stock returns through the merger episode. To the best of our knowledge, our paper is the first that examines the impact of takeovers on stock returns and firm-level betas. ${ }^{2}$

The remainder of the paper is organized as follows. Section II presents the basic model of mergers and acquisitions. Section III derives the optimal exercise policies for the firms' real options. Section IV derives closed-form results on the dynamics of beta and long-run performance. Section V tests our predictions. Section VI concludes. Technical developments are gathered in the Appendix.

\footnotetext{
${ }^{2}$ From a modelling perspective, our paper also relates to the literature that analyzes asset pricing implications of corporate investment decisions using real options models [see e.g. Berk, Green, and Naik (1999), Carlson, Fisher, and Giammarino (2005a, 2005b), Cooper (2005), or Zhang (2005)].
} 


\section{A dynamic model of takeovers}

Consider two public firms, $B$ and $T$, with capital stocks $K_{B}$ and $K_{T}$ and stock market valuations $S_{B}$ and $S_{T}$. Each firm owns assets in place that generate a random stream of cash flows as well as an option to enter a takeover deal. Accordingly, the stock market valuation of each firm has two components and is given by

$$
S_{B}(X, Y)=K_{B} X+G_{B}(X, Y), \text { and } S_{T}(X, Y)=K_{T} Y+G_{T}(X, Y)
$$

where the first term on the right hand side of these equations is the present value of the cash flows generated by assets in place, denoted by $X$ and $Y$ per unit of capital, and the second term is the surplus associated with a potential restructuring. In the analysis below, $B$ and $T$ are respectively the bidding firm and the target firm. These roles are exogenously assigned and are determined by firms' specific characteristics, not modelled in this paper.

Throughout the paper, management acts in the best interest of stockholders and seeks to maximize the intrinsic firm value when determining the timing and terms of takeovers. In our base case environment, we consider that takeovers create value by generating synergy gains. Notably, we follow the literature that emphasizes the role played by efficiency and capital reallocation in determining the timing and terms of takeovers in assuming that net synergy gains are given by

$$
G(X, Y)=K_{T}[\alpha(X-Y)-\omega Y], \quad(\alpha, \omega) \in \mathbb{R}_{++}^{2} .
$$

In this equation, the parameter $\alpha>0$ represents the improvement in the value of the target firm after the takeover. The factor $\omega>0$ accounts for proportional sunk costs of implementation paid at the time of the takeover (introducing costs for the bidder would not affect any of the results). This equation suggests that acquiring firms are better performers $(X>Y)$ and that the takeover results in a more efficient allocation of resources. This specification is consistent with the fact that acquirers generally have higher Tobin's $q$ than their target companies [see Lang, Stulz and Walking (1989), Maksimovic and Phillips (2001) or Andrade and Stafford (2004) for evidence supporting this view]. It need not imply however large differences in market-to-book ratios as the values of the bidding and target firms also reflect the potential benefits associated with the takeover (which reduces the relative differences in market values between the two firms). In the model extensions we will consider additional dimensions of the takeover process that will either increase the takeover surplus, such as follow-up operating options, or reduce it, such as competition for the target firm.

The timing of takeovers typically depends on the combined takeover surplus as well as its allocation among participating firms. It also depends on several dimensions of 
the firms' environment such as ongoing uncertainty or the ability to reverse decisions. In this paper, we consider that takeovers are irreversible (unless the firm has a followup disinvestment option). In addition, we assume that the present value of the cash flows from the core businesses of participating firms evolves according to the stochastic differential equation:

$$
d A(t)=\left(\mu_{A}-\delta_{A}\right) A(t) d t+\sigma_{A} A(t) d W_{A}(t), \quad A=X, Y,
$$

where $\mu_{A}, \delta_{A}>0$ and $\sigma_{A}>0$ are constant parameters and $W_{X}$ and $W_{Y}$ are standard Brownian motions. The correlation coefficient between $W_{X}$ and $W_{Y}$ is constant, equal to $\rho \in(-1,1)$. In the analysis that follows, we consider that there exist two traded assets with market betas $\beta_{X}$ and $\beta_{Y}$, which are perfectly correlated with $X$ and $Y$, and a riskless bond with dynamics $d B_{t}=r B_{t} d t$. This allows us to construct a risk neutral measure $\mathcal{Q}$ under which the drift rates of $X$ and $Y$ are given by $r-\delta_{A}$, for $A=X, Y$.

\section{The timing and terms of takeovers}

\section{A. Base case}

In our model, takeovers present participants in the deal with an option to exchange one asset for another - they can exchange their shares in the initial firm for a fraction of the shares of the merged entity. As a result, the timing of takeover deals is determined by the restructuring strategy that maximizes the value of the exchange option. To solve the optimization problem of participating firms, it will be useful to rewrite the surplus created by the takeover as: $G(X, Y)=Y K_{T}[\alpha R-(\alpha+\omega)]$, with $R \equiv X / Y$. This expression shows that we can solve shareholders' optimization problem by looking only at the relative valuations of the bidding and target firms' core businesses $R$. In addition, because the value of the surplus increases with the ratio of core business valuations $R$, the value-maximizing strategy is to enter the takeover deal when $R$ reaches a higher threshold $R^{m}$.

One essential difference between the option to enter the takeover deal and standard real options is that the former involves two firms. This implies that the timing and terms of the takeover have to be derived in two steps. The first step determines the optimal takeover threshold for each set of shareholders given a sharing rule $\xi$ for the takeover surplus. One obtains a pair $\left(\xi, R^{B}(\xi)\right)$ for bidding shareholders and a pair $\left(\xi, R^{T}(\xi)\right)$ for target shareholders. The second step consists in deriving endogenously the sharing rule by making the two takeover thresholds coincide: $R^{B}(\xi)=R^{T}(\xi)=R^{*}\left(\xi^{*}\right)$. The equilibrium $\left(\xi^{*}, R^{*}\left(\xi^{*}\right)\right)$ is optimal for both players and is such that both players want to enter the game at the same time. This is the only renegotiation proof equilibrium [see also Lambrecht (2004) and Morellec and Zhdanov (2005)]. 
Suppose that the takeover agreement specifies that a fraction $\xi$ of the new firm accrues to bidding shareholders after the takeover and denote by $V(X, Y)$ the value of the combined firm after the takeover, defined by

$$
V(X, Y)=K_{B} X+K_{T} Y+\alpha(X-Y) K_{T}
$$

When exercising the option to merge, bidding shareholders give up their claims in their firm, worth $K_{B} X$, for a fraction $\xi$ of the new entity net of the sunk implementation costs, worth $\xi\left[V(X, Y)-\omega Y K_{T}\right] .^{3}$ The payoff from exercising the option to merge for bidding shareholders is thus given by: $\xi\left[V(X, Y)-\omega Y K_{T}\right]-K_{B} X$. This implies that we can write their optimization problem as:

$$
O_{B}^{m}(X, Y)=\sup _{\mathcal{T}_{B}^{m}} \mathbb{E}_{\mathcal{Q}}\left\{e^{-r \mathcal{T}_{B}^{m}}\left[\xi\left(V\left(X_{\mathcal{T}_{B}^{m}}, Y_{\mathcal{T}_{B}^{m}}\right)-\omega Y_{\mathcal{T}_{B}^{m}} K_{T}\right)-K_{B} X_{\mathcal{T}_{B}^{m}}\right]\right\}
$$

where $\mathbb{E}_{\mathcal{Q}}$ denotes the expectation operator associated with the risk neutral measure $\mathcal{Q}$ and $\mathcal{T}_{B}^{m}$ is the first time to reach the takeover threshold selected by bidding shareholders. Similarly, target shareholders can exchange their initial claims, worth $K_{T} Y$, for a fraction $1-\xi$ of the new entity. Hence the optimization problem of target shareholders can be written as

$$
O_{T}^{m}(X, Y)=\sup _{\mathcal{T}_{T}^{m}} \mathbb{E}_{\mathcal{Q}}\left\{e^{-r \mathcal{T}_{T}^{m}}\left[(1-\xi)\left(V\left(X_{\mathcal{T}_{B}^{m}}, Y_{\mathcal{T}_{B}^{m}}\right)-\omega Y_{\mathcal{T}_{B}^{m}} K_{T}\right)-K_{T} Y_{\mathcal{T}_{T}^{m}}\right]\right\} .
$$

where $\mathcal{T}_{T}^{m}$ is the first time to reach the threshold selected by target shareholders.

Denote by $\vartheta>1$ and $\nu<0$ the positive and negative roots of the quadratic equation:

$$
\frac{1}{2}\left(\sigma_{X}^{2}-2 \rho \sigma_{X} \sigma_{Y}+\sigma_{Y}^{2}\right)(\vartheta-1) \vartheta+\left(\delta_{Y}-\delta_{X}\right) \vartheta=\delta_{Y}
$$

and define

$$
\Pi(z)=z\left(\beta_{X}-\beta_{Y}\right)+\beta_{Y}
$$

for $z=\vartheta, \nu$. Solving these optimization problems yields the following result. (Proofs for all propositions are given in the Appendix).

Proposition 1 The value-maximizing restructuring policy for participating firms is to merge when the ratio of core business valuations $R \equiv X / Y$ reaches the cutoff level

$$
R^{m}=\frac{\vartheta}{\vartheta-1} \frac{\omega+\alpha}{\alpha}
$$

\footnotetext{
${ }^{3}$ This specification implies that each firm incurs a cost at the time of the takeover as in Lambrecht (2004). In the Appendix we show that when bidding shareholders pay the full takeover cost, the sharing rule for the combined firm adjusts to make up their loss. As a result this assumption has not bearing on the timing of the takeover or on the surplus it creates.
} 
for which $R_{T}^{m}=R_{B}^{m}$. Denote by $\mathcal{T}^{m}$ the first time to reach the takeover threshold. The beta of the shares of bidding shareholders satisfies

$$
\beta_{t}= \begin{cases}\frac{K_{B} X \beta_{X}+\Pi(\vartheta) O_{B}^{m}(X, Y)}{K_{B} X+O_{B}^{m}(X, Y)}, & \text { for } t<\mathcal{T}^{m} \\ \frac{v(X, Y)}{V(X, Y)}, & \text { for } t>\mathcal{T}^{m}\end{cases}
$$

where $\Pi(\cdot)$ is defined in (5) and

$$
v(X, Y)=\beta_{X} X V_{X}(X, Y)+\beta_{Y} Y V_{Y}(X, Y),
$$

and where, for $t<\mathcal{T}^{m}$, the value of the restructuring option for bidding shareholders is given by

$$
O_{B}^{m}(X, Y)=Y\left[\xi\left(V\left(R^{m}, 1\right)-\omega K_{T}\right)-K_{B} R^{m}\right]\left(\frac{R}{R^{m}}\right)^{\vartheta} .
$$

Proposition 1 highlights several interesting features of takeover deals. First, and as shown in Morellec and Zhdanov (2005), the timing of takeovers depends on the growth rate and volatility of cash flows from the firms' core businesses as well as the correlation coefficient $\rho$ between business risks. In particular, holding their covariance fixed, a greater variance for the changes in $X$ and $Y$ implies more uncertainty over their ratio, and hence an increased incentive to wait. Holding their variances fixed, a greater covariance between the changes in $X$ and $Y$ implies less uncertainty over their ratio, and hence a reduced incentive to wait. These timing effects come from the optionality of the decision to enter the takeover deal and are reflected in the factor $\vartheta /(\vartheta-1)$, which captures the option value of waiting. If this option had no value, shareholders would follow the simple NPV rule, according to which one should invest as soon as the takeover surplus is positive (i.e. as soon as $R>(\omega+\alpha) / \alpha$ ).

Second, the value of the option to enter the takeover deal consists of two components. The first component is the surplus accruing to shareholders at the time of the option exercise. The second one is the present value of $\$ 1$ contingent on the option being exercised (i.e. a stochastic discount factor), which takes the familiar expression $R^{\vartheta}\left(R^{m}\right)^{-\vartheta}$. Third, the beta of the shares of bidding shareholders evolves stochastically through the merger episode. In particular, the beta dynamics are driven by changes in asset values and the decision to enter the takeover deal $\left(\right.$ at $t=\mathcal{T}^{m}$ ). By merging with the target, bidding shareholders exercise their call option to enter the takeover deal. Since call options are riskier than the assets that they are written on, economic intuition suggests that this option exercise should trigger a reduction in the shares' beta. As shown in Section IV, the magnitude and sign of the change in beta at the time of the option exercise depends on several factors including the potential heterogeneity in business risk between bidding and target firms. 


\section{B. Extensions}

In this section, we present two extensions of the basic model that aim at capturing some of the main features of takeover deals. In the first extension, we incorporate the follow-up operating options that characterize a large fraction of takeover deals. In the second extension we incorporate competition and asymmetric information to generate abnormal announcement returns. In section 4 we show that adding these features does not affect our conclusions regarding the behavior of firm-level betas in takeover deals.

\section{Mergers with follow-up options}

Consider that after the takeover the successful bidder holds both a real option to expand operations by a factor $\Lambda$ at a cost $\lambda(X+Y)$ and a real option to divest fraction $1-\Theta$ of its assets (or shut down if $\Theta=0$ ) at a price $\theta(X+Y) .{ }^{4}$ Because the takeover surplus depends on the operating options available to the merged entity, the derivation of valuemaximizing strategies for such deals proceeds in two steps. The first step determines the exercise strategies for the expansion and contraction options of the merged entity. The second step derives the equilibrium restructuring strategies, taking the optimal expansion and disinvestment strategies as given.

Denote by $V(X, Y)$ the value of the combined firm ignoring the follow-up options, defined by equation (4). For any values of $X$ and $Y$, the payoff of the disinvestment option and expansion options are respectively given by

$A(X, Y)=\theta(X+Y)-(1-\Theta) V(X, Y)$ and $B(X, Y)=(\Lambda-1) V(X, Y)-\lambda(X+Y)$.

Again the payoff from the options to divest assets and to expand satisfy $A(X, Y)=$ $Y A(R, 1)$ and $B(X, Y)=Y B(R, 1)$. As a result, the value-maximizing strategy can be characterized by two constant thresholds $R^{d}$ and $R^{e}$, with $R^{e}>R^{d}$, such that the firm should divest assets if and when $(R(t))_{t \geq 0}$ reaches $R^{d}$ before $R^{e}$ or expand if it reaches $R^{e}$ before reaching $R^{d}$. Denote by $\mathcal{T}^{d}$ the first passage time to the disinvestment threshold and by $\mathcal{T}^{e}$ the first passage time to the expansion threshold. We can write the value of the firm's portfolio of real options after the takeover as

$O^{c}(X, Y)=\sup _{\left\{\mathcal{T}^{d}, \mathcal{T}^{e}\right\}} \xi \mathbb{E}_{\mathcal{Q}}\left\{1_{\mathcal{T}^{d}<\mathcal{T}^{e}}\left[e^{-r \mathcal{T}^{d}} A\left(X_{\mathcal{T}^{d}}, Y_{\mathcal{T}^{d}}\right)\right]+1_{\mathcal{T}^{e}<\mathcal{T}^{d}}\left[e^{-r \mathcal{T}^{e}} B\left(X_{\mathcal{T}^{e}}, Y_{\mathcal{T}^{e}}\right)\right]\right\}$

where $1_{\omega}$ is the indicator function of $\omega$. The first term in the curly brackets represents the value of the option to divest. The second term accounts for the value of the option

\footnotetext{
${ }^{4}$ In this section, we implicitly assume that in some states of nature these assets are worth more to a buyer, and the buyer is hence willing to pay more for them. Maksimovic and Phillips (2001) show that partial-firm asset sales improve the productivity of transferred assets by effectively redeploying assets from firms that have less of an ability to exploit them to firms with more of an ability.
} 
to expand. As before, this expression shows that the value of the firm's follow-up options is a product of two factors; that is, the surplus associated with the follow-up option at the time of exercise and the present value of $\$ 1$ contingent on exercise.

Consider next the value of the option to merge and denote by $S^{c}(X, Y)$ the value of the firm after the takeover net of the sunk investment costs, defined by

$$
S^{c}\left(X_{\mathcal{T}_{B}^{m}}, Y_{\mathcal{T}_{B}^{m}}\right)=V\left(X_{\mathcal{T}_{B}^{m}}, Y_{\mathcal{T}_{B}^{m}}\right)+O^{c}\left(X_{\mathcal{T}_{B}^{m}}, Y_{\mathcal{T}_{B}^{m}}\right)-\omega Y_{\mathcal{T}_{B}^{m}} K_{T}
$$

When exercising the option to merge, bidding shareholders give up their claims in their firm, worth $K_{B} X$, for a fraction $\xi$ of the new entity. As a result, their optimization problem can be written as

$$
O_{B}^{m}(X, Y)=\sup _{\mathcal{T}_{B}^{m}} \mathbb{E}_{\mathcal{Q}}\left\{e^{-r \mathcal{T}_{B}^{m}}\left[\xi S^{c}\left(X_{\mathcal{T}_{B}^{m}}, Y_{\mathcal{T}_{B}^{m}}\right)-K_{B} X_{\mathcal{T}_{B}^{m}}\right]\right\}
$$

where $\mathcal{T}_{B}^{m}$ is the first time to reach the takeover threshold selected by bidding shareholders. Similarly, the optimization problem of target shareholders can be written as

$$
O_{T}^{m}(X, Y)=\sup _{\mathcal{T}_{T}^{m}} \mathbb{E}_{\mathcal{Q}}\left\{e^{-r \mathcal{T}_{T}^{m}}\left[(1-\xi) S^{c}\left(X_{\mathcal{T}_{B}^{m}}, Y_{\mathcal{T}_{B}^{m}}\right)-K_{T} Y_{\mathcal{T}_{T}^{m}}\right]\right\}
$$

where $\mathcal{T}_{T}^{m}$ is the first time to reach the threshold selected by target shareholders.

Denote by $\mathcal{L}(R)$ the present value of $\$ 1$ to be received the first time $R$ reaches $R^{d}$, conditional on $R$ reaching $R^{d}$ before reaching $R^{e}$. In addition, denote by $\mathcal{H}(R)$ the present value of one dollar to be received the first time that $R$ reaches $R^{e}$, conditional on $R$ reaching $R^{e}$ before $R^{d}$. We then have the following result.

Proposition 2 The value-maximizing restructuring policy is to merge when the ratio of core business valuations $R \equiv X / Y$ reaches the cutoff level $R^{m}$ solving

$$
K_{T}\left[\alpha R^{m}(\vartheta-1)-\vartheta(\alpha+\omega)\right]+(\vartheta-\nu)\left(R^{m}\right)^{\nu} J(z)=0,
$$

where

$$
J(z)=Y\left[\left(R^{e}\right)^{z} A\left(R^{d}, 1\right)-\left(R^{d}\right)^{z} B\left(R^{e}, 1\right)\right]\left[\left(R^{e}\right)^{\vartheta}\left(R^{d}\right)^{\nu}-\left(R^{e}\right)^{\nu}\left(R^{d}\right)^{\vartheta}\right]^{-1},
$$

and for which $R_{T}^{m}=R_{B}^{m}$. The value-maximizing expansion and disinvestment thresholds $R^{e}$ and $R^{d}$ are defined by $R^{e}=y R^{d}$ where $y>1$ solves

$$
\begin{aligned}
& \frac{\nu}{\nu-1} \frac{\left[y^{\vartheta}(1-\Theta)+(\Lambda-1)\right](1-\alpha) K_{T}-\lambda-\theta y^{\vartheta}}{\theta y^{\vartheta}+\lambda y-\left[(1-\Theta) y^{\vartheta}+(\Lambda-1) y\right]\left(K_{B}+\alpha K_{T}\right)} \\
= & \frac{\vartheta}{\vartheta-1} \frac{\left[y^{\nu}(1-\Theta)+(\Lambda-1)\right](1-\alpha) K_{T}-\lambda-\theta y^{\nu}}{\theta y^{\nu}+\lambda y-\left[(1-\Theta) y^{\nu}+(\Lambda-1) y\right]\left(K_{B}+\alpha K_{T}\right)}
\end{aligned}
$$


and

$$
R^{d}=\frac{\nu}{\nu-1} \frac{\left[y^{\vartheta}(1-\Theta)+(\Lambda-1)\right](1-\alpha) K_{T}-\lambda-\theta y^{\vartheta}}{\theta y^{\vartheta}+\lambda y-\left[(1-\Theta) y^{\vartheta}+(\Lambda-1) y\right]\left(K_{B}+\alpha K_{T}\right)} .
$$

The beta of the shares of bidding shareholders is given by

$$
\beta_{t}= \begin{cases}\frac{K_{B} X \beta_{X}+\Pi(\vartheta) O_{B}^{m c}(X, Y)}{K_{B} X+O_{B}^{m}(X, Y)}, & t<\mathcal{T}^{m} \\ \frac{v(X, Y)+\left(\beta_{X}-\beta_{Y}\right)\left[\nu R^{\nu} J(\vartheta)-\vartheta R^{\vartheta} J(\nu)\right]+\beta_{Y} O^{c}(X, Y)}{V(X, Y)+O^{c}(X, Y)}, & t \in\left[\mathcal{T}^{m}, \mathcal{T}^{e} \wedge \mathcal{T}^{d}\right] \\ \frac{v(X, Y)}{V(X, Y)}, & t>\mathcal{T}^{e} \wedge \mathcal{T}^{d}\end{cases}
$$

where $\Pi(\cdot)$ is defined in (5), $O_{B}^{m c}(X, Y)=O_{B}^{m}(X, Y)+\xi O^{c}(X, Y)$ for $t<\mathcal{T}^{m}$, and

$$
O^{c}(X, Y)= \begin{cases}Y\left[\mathcal{L}\left(R^{m}\right) A\left(R^{d}, 1\right)+\mathcal{H}\left(R^{m}\right) B\left(R^{e}, 1\right)\right]\left(\frac{R}{R^{m}}\right)^{\vartheta}, & t<\mathcal{T}^{m} \\ Y\left[\mathcal{L}(R) A\left(R^{d}, 1\right)+\mathcal{H}(R) B\left(R^{e}, 1\right)\right] & t \in\left[\mathcal{T}^{m}, \mathcal{T}^{e} \wedge \mathcal{T}^{d}\right]\end{cases}
$$

In these expressions, the stochastic discount factors $\mathcal{L}(R)$ and $\mathcal{H}(R)$ are defined by

$$
\mathcal{L}(R)=\frac{\left(R^{e}\right)^{\vartheta} R^{\nu}-\left(R^{e}\right)^{\nu} R^{\vartheta}}{\left(R^{e}\right)^{\vartheta}\left(R^{d}\right)^{\nu}-\left(R^{e}\right)^{\nu}\left(R^{d}\right)^{\vartheta}}, \text { and } \mathcal{H}(R)=\frac{R^{\vartheta}\left(R^{d}\right)^{\nu}-R^{\nu}\left(R^{d}\right)^{\vartheta}}{\left(R^{e}\right)^{\vartheta}\left(R^{d}\right)^{\nu}-\left(R^{e}\right)^{\nu}\left(R^{d}\right)^{\vartheta}},
$$

and $V(X, Y), v(X, Y)$ and $O_{B}^{m}(X, Y)$ are defined as in Proposition 1.

Proposition 2 provides the value-maximizing merger and operating policies when the takeover provides the new entity with a real option to expand or divest assets. The value of the follow-up option reported in Proposition 2 takes the familiar functional form: It is the product of the surplus created by the follow-up option (to divest or expand) and a stochastic discount factor. In this case however this discount factor is itself the product of two terms, one reflecting the probability and the timing of the merger (given by $(R)^{\vartheta}\left(R^{m}\right)^{-\vartheta}$ ) and the other reflecting the probability and the timing of the exercise of the follow-up option, conditional on the takeover being consummated (given by $\mathcal{L}\left(R^{m}\right)$ for the option to divest and by $\mathcal{H}\left(R^{m}\right)$ for the option to expand).

The main difference between Proposition 1 and Proposition 2 lies in the beta of the shares of bidding shareholders. As in Proposition 1, the beta evolves as a function of changes in asset values and value-maximizing investment decisions (at $\mathcal{T}^{m}$ and $\mathcal{T}^{e} \wedge \mathcal{T}^{d}$ ). In this case however, the option to disinvest is akin to a put option. Because the elasticity $\nu$ of the put option value with respect to the value of the underlying asset is negative, exercising the disinvestment option may increase firm risk and thus expected stock returns. Interestingly, once the operating option is exercised (i.e. for $t>\mathcal{T}^{e} \wedge \mathcal{T}^{d}$ ), the functional form of the betas for the shares of bidding shareholders does not depend on the past nature of this option. Thus, while operating options affect the size of the new entity, they should not affect long-run betas once they are exercised. 


\section{Mergers with multiple bidders and asymmetric information}

This subsection extends the analysis reported in subsection A in two dimensions. First we consider that several potential acquirers, that differ in terms of synergy benefit $\alpha$, can compete for the target. ${ }^{5}$ For clarity of exposition and without loss in generality, we will consider a situation in which there are two potential acquirers, firm 1 and firm 2 . Second, we consider that management has complete information regarding the potential benefits of the takeover, but can not communicate this information to shareholders [as in Carlson, Fisher and Giammarino (2005b) and Morellec and Zhdanov (2005)]. Outside stockholders have imperfect information and decide to accept or reject takeover bids based on the informed manager's recommendation. Because insider trading laws (and possibly wealth constraints) prohibit managers from trading on their inside information, managers do not sell or buy their own stock to restore efficient pricing. Thus, market prices reflect the information set of uninformed investors.

In such an environment, participating shareholders face two sources of uncertainty. The first source of uncertainty relates, as before, to the cash flows from the firms' core businesses. The second source of uncertainty relates to the parameters driving the synergy gain. In particular, we consider that $\omega$ is observable to all investors. By contrast, $\alpha$ is only observable to the managers of participating firms. ${ }^{6}$ While outside investors can not observe $\alpha$, they have prior beliefs about its possible values and update these beliefs by observing the behavior of the two firms. Specifically, as shown in Proposition 1, the value-maximizing policy for each $\alpha$ is to invest when the process $(R(t))_{t \geq 0}$ first crosses a monotonic threshold $R^{*}(\alpha)$ from below. At the time of the restructuring, investors observe $(R(t))_{t \geq 0}$ and infer the value of $\alpha$ using the mapping $\alpha \mapsto R^{*}(\alpha)$. Before then, they learn about the value created by the takeover by observing the path of $(R(t))_{t \geq 0}$. When $(R(t))_{t \geq 0}$ reaches a new peak and the firm does not invest, the market revises its beliefs regarding the true value of $\alpha$. In addition, since part of the uncertainty remains unresolved until the announcement of the takeover, the model generates abnormal returns around takeover announcements.

To determine the timing and terms of the takeover in this environment, we first examine the optimization problem of bidding shareholders. Once the takeover contest

\footnotetext{
${ }^{5}$ In our model, targets are scarce and competition between multiple bidders hurts the acquirer. See Bradley, Desai, and Kim (1988) and De, Fedenia, and Triantis (1996) for evidence supporting this view.

${ }^{6} \mathrm{~A}$ number of factors may explain this informational advantage. First, as emphasized by Jensen and Meckling (1992), the transfer of information may involve costly delays, and for some decisions such costs can be excessive, including sometimes the complete loss of opportunities. Second, management's knowledge about future market demand evolves continuously, and it may be too costly to frequently communicate this information. Finally, this information may simply be "soft" in the sense of Stein (2002) and cannot be communicated easily to investors (for example it might relate to management's ability to make different corporate cultures, governance systems, or established brands fit together).
} 
is initiated, both bidders submit their bids in the form of the fraction of the new firm's equity to be owned by target shareholders after the takeover. The maximum value of that fraction, or maximum price that a bidder is willing to pay, makes the bidder indifferent between winning and losing the takeover contest. Assume that both bidders belong to the same industry so that their cash flows are driven by the same process $X$. Then the breakeven stake of bidder $i$ solves

$$
\xi_{b e i}\left(\alpha_{i}\right)\left[V\left(X, Y ; \alpha_{i}\right)-\omega Y K_{T}\right]-K_{B} X=0, \quad i=1,2 .
$$

Assume that we adopt a Nash equilibrium and let $V\left(X, Y ; \alpha_{1}\right)>V\left(X, Y ; \alpha_{2}\right)$ (i.e. $\left.\alpha_{1}>\alpha_{2}\right)$. Depending on parameter values, two mutually exclusive equilibria may arise. In the first equilibrium, the losing bidder (firm 2) is weak in the sense that the value associated with the share offered to target shareholders by the winning shareholders is greater than the breakeven value of the weaker bidder:

$$
(1-\xi)\left[V\left(X, Y ; \alpha_{1}\right)-\omega Y K_{T}\right]>\left(1-\xi_{b e 2}\right)\left[V\left(X, Y ; \alpha_{2}\right)-\omega Y K_{T}\right] .
$$

In this equilibrium, the takeover takes place the first time the ratio of core business valuations reaches the threshold $R^{m}\left(\alpha_{1}\right)$ defined in Proposition 1. Moreover, bidding shareholders get a fraction $\xi\left(\alpha_{1}\right)$ of the combined firm, as defined in Proposition 1.

In the second equilibrium, the losing bidder is strong and the winning bidder has to offer an ownership stake in the combined firm to the target such that the value to the target of dealing with bidder 1 is not less than that of dealing with bidder 2. Denote by $\xi_{1 \max }(X, Y)$ the maximum share of the new entity that the winning bidder can keep. This share is defined by:

$$
\underbrace{\left[V\left(X, Y ; \alpha_{1}\right)-\omega Y K_{T}\right]\left[1-\xi_{1 \max }(X, Y)\right]}_{\text {Value of dealing with bidder } 1}=\underbrace{V\left(X, Y ; \alpha_{2}\right)-\omega Y K_{T}-K_{B} X}_{\text {Maximum value with bidder } 2}
$$

which can also be expressed as

$$
\xi_{1 \max }(X, Y)=\frac{K_{B} X+K_{T}\left(\alpha_{1}-\alpha_{2}\right)(X-Y)}{V\left(X, Y ; \alpha_{1}\right)-\omega Y K_{T}} .
$$

In this equilibrium, the timing of the takeover is then defined by the equality

$$
\xi_{1 \max }(R, 1)=\frac{(\vartheta-1) R\left(K_{B}+\alpha_{1} K_{T}\right)-\vartheta\left(\alpha_{1}+\omega\right) K_{T}}{(\vartheta-1) R\left(K_{B}+\alpha_{1} K_{T}\right)-\vartheta\left(\alpha_{1}+\omega-1\right) K_{T}},
$$

where the right hand side of this equation has been obtained by solving the unconstrained reaction function of target shareholders, $R_{T}^{m}$ defined in Appendix A, for $\xi$. We then have the following result. 
Proposition 3 When there is competition for the target and $\alpha_{1}>\alpha_{2}$, the takeover takes place the first time the ratio of core business valuations reaches the threshold $R^{*}$ defined by $R^{*}=\min \left[R^{m}\left(\alpha_{1}\right), R_{\text {comp }}\right]$, where $R^{*}=R^{m}\left(\alpha_{1}\right)$ defined in Proposition 1 when the losing bidder is weak and $R^{*}=R_{\text {comp }}$ solving

$$
\xi_{1 \max }(R, 1)=I\left[R_{T}^{m}(\xi)\right]
$$

when the losing bidder is strong. In this equation, $I(\cdot)$ inverts $R_{T}^{m}(\xi)$, meaning that $I[R(\xi)]=\xi$ for all $\xi$, and $R_{T}^{m}(\xi)$ is the takeover threshold selected by target shareholders for bidder 1 in the absence of competition. Moreover, the share of the combined firm accruing to bidding shareholders is given by

$$
\xi=\min \left[\xi_{1 \max }\left(R^{*}, 1\right), \frac{\left(\omega+\alpha_{1}\right) K_{B}}{\left(\omega+\alpha_{1}\right) K_{B}+\alpha_{1} K_{T}}\right],
$$

where the min function takes a value equal to its first argument when competition erodes the ownership share of bidding shareholders and a value equal to its second argument otherwise. When competition erodes the ownership share of bidding shareholders, the beta of their shares before the takeover is given by

$$
\beta_{t}=\frac{K_{B} X \beta_{X}+\Pi(\vartheta) O_{B i}^{m}(X, Y)}{K_{B} X+O_{B i}^{m}(X, Y)}, \quad \text { for } t<\mathcal{T}^{m},
$$

where $\Pi(\cdot)$ is defined in (5), and, for $t \leq \mathcal{T}^{m}$, we have

$$
O_{B i}^{m}(X, Y)=\sum_{\alpha_{1} \in \Omega_{1}^{\mathrm{p}}(t)} \sum_{\alpha_{2} \in \Omega_{2}^{\mathrm{p}}(t)} \operatorname{Pr}\left(\alpha_{1}, \alpha_{2}\right) 1_{\alpha_{1}>\alpha_{2}} Y K_{T}\left(\alpha_{1}-\alpha_{2}\right)\left(R^{*}-1\right)\left(\frac{R}{R^{*}}\right)^{\vartheta},
$$

and where $\Omega_{i}^{\mathrm{p}}(t)$ is the time-t posterior sample space of $\alpha_{i}, i=1,2$. For $t>\mathcal{T}_{i}^{m}$, the beta of the shares of bidding shareholders is given as in Proposition 1.

Proposition 3 highlights several important results. First, competition for the target firm erodes the ownership stake of bidding shareholders. In particular, when the losing bidder is "strong," the ownership share of bidding shareholders in the new entity is given by $\xi_{1 \max }\left(R^{*}, 1\right)$, which is lower than the share they would have had without competition. In addition, competition speeds up the takeover process. That is, the equilibrium takeover threshold when the losing bidder is "strong" is $R_{\text {comp }}$, which is lower than the equilibrium threshold in the absence of competition.

Second, the value $O_{B i}^{m}(X, Y)$ of the option to merge is again equal to the product of the surplus accruing to bidding shareholders at the time of the takeover and a stochastic discount factor. When there is competition for the target and the second bidder is strong, the ownership share of the winning shareholders in the new entity 
is given by $\xi_{1 \max }(X, Y)$, defined in equation (9). This implies that the surplus that winning shareholders extract at the time of the takeover is equal to the value of the combined firm minus the maximum value of dealing with the losing bidder. As shown in Proposition 3 this quantity is equal to: $Y K_{T}\left(\alpha_{1}-\alpha_{2}\right)\left(R^{*}-1\right)$. Because the value of the synergy parameter is unknown to outside stockholders before the takeover, the value of the option to merge is a weighted average of all possible option values (i.e. over all possible values $\alpha_{i}$ that have not been eliminated through the updating of beliefs).

Third, although competition affects the sharing of firm value between target and bidding shareholders, it does not affect the functional form of total equity value after the takeover. Thus competition has no impact on the functional form of the betas after the takeover even though it affects the timing of the changes in betas. This is apparent from the expressions reported in Propositions 1 and 3. Obviously, competition has an impact on the dynamics of firm-level betas before the takeover through its effects on the "moneyness" of the restructuring option $O_{B i}^{m}(X, Y)$ and the equilibrium sharing rule for the combined takeover surplus.

\section{Empirical predictions}

\section{A. Parameter calibration}

In this section, we derive the implications of the model for the dynamics of firm-level betas and expected stock returns. While most of these implications are derived from closed form results, some will be illustrated through numerical examples. To determine the values of the quantities of interest, we thus need to select parameter values for the risk-free interest rate $r$, the payout rates $\delta_{X}$ and $\delta_{Y}$, the diffusion coefficients of the core business valuations $\sigma_{X}$ and $\sigma_{Y}$, the correlation coefficient between core business valuations $\rho$, the betas of core assets $\beta_{X}$ and $\beta_{Y}$, the synergy parameter $\alpha$, the takeover premium $\omega$, and the characteristics of the operating options $(\Lambda, \lambda)$ and $(\Theta, \theta)$. This section describes how parameters are calibrated to satisfy certain criteria and match a number of sample characteristics of the Compustat and CRSP data. Due to the lack of precise data on their value, the parameters in our analysis must be regarded as approximate. Table 1 summarizes our parameter choices.

The risk free rate is taken as a historical average from the yield curve on Treasury bonds. Relying on historical data for the U.S., we select payout rates on core assets that provide average dividend yields consistent with observed yields [see Ibbotson Associates (2002)]. The diffusion parameters of core assets are set to 0.20 . This implies that the average of equity return volatilities is $25 \%$, consistent with time series averages on the S\&P500 [see e.g. Strebulaev (2006)]. While the model allows us to take any size for 
the bidding and target firms we focus thereafter on mergers of equals by assuming that $K_{B}=K_{T}=1$. Firms typically differ in their systematic risk, represented by beta. In the analysis of stock returns, we normalize the beta of the target's core assets $\beta_{Y}$ to 1 and examine alternatively cases in which $\beta_{X}$ is greater (1.5) or smaller (0.5) than 1.

\begin{tabular}{lll}
\hline \hline TABLE 1 & SOURCE & PARAMETER CHOICES \\
\hline risk free interest rate & data & $r=0.06$ \\
payout rates & data & $\delta_{X}=0.005 ; \delta_{Y}=0.035$ \\
volatilities of core assets & data & $\sigma_{X}=\sigma_{Y}=0.2$ \\
correlation coefficient & normalized & $\rho=0.75$ \\
betas of core assets & normalized & $\beta_{Y}=1$ \\
efficiency parameter & data & $\alpha / \omega=1$ \\
capital stocks & normalized & $K_{B}=K_{T}=1$ \\
expansion option & data & $\Lambda=1.15 ; \lambda=0.2$ \\
divestiture option & data & $\Theta=0.85 ; \theta=0.1$ \\
\hline \hline
\end{tabular}

The parameter values for the firm's operating options are selected in such a way that the firm can either increase or decrease its size by the same fraction, i.e. $\Lambda-1=$ $1-\Theta$. Since there are more data available for calibrating the parameter values of the divestiture option, we will start by calibrating the fraction $\Theta$ of assets remaining after the asset sale. In their sample of 102 distressed firms, Asquith, Gertner and Scharfstein (1994) report asset sales averaging around $12 \%$ of the book value of assets. Moreover, 21 companies in their sample sold more than $20 \%$ of their assets, with a median level of asset sales of $48 \%$ among these firms. Lang, Poulsen, and Stulz (1995) study 93 asset sales of 77 (non-distressed) firms and obtain similar quantitative estimates. Consistent with these data points, we approximate the fraction of assets sold by setting $\Theta=0.85$ in our model. For symmetry, we impose $\Lambda-1=0.15$, which is consistent with the estimates reported by Hennessy (2004) regarding investment levels. In addition, we pick parameter values for $\lambda$ and $\theta$ such that the firm has a $50 \%$ probability of exercise of the follow-up options over a three-year horizon following the takeover.

We calibrate the parameters $\alpha$ and $\omega$ using the premium paid to target shareholders at the time of the takeover. The premium to the target in a takeover can range from 10 to $50 \%$ [see e.g. Bradley, Desai, and Kim (1988) and Schwert (2000)]. In our model, the premium paid to the target above the value of its core assets is given by:

$$
P_{T}=(1-\xi) K_{T}^{-1} S^{i}\left(R_{\mathcal{T}^{m}}, 1\right)-1, \quad i=e, d,
$$

where $\xi$ is the share of the combined firm accruing to bidding shareholders. This yields a ratio of $\alpha / \omega=1$ for a premium of $30 \%$. 


\section{B. Asset pricing implications}

The decision of whether to merge has important consequences for the systematic risk of the firm's operations and expectations of long-run stock returns. Using the results in Propositions 1, 2, and 3, we examine how the return characteristics of the target firm and stockholders' option exercise decisions dynamically impact firms' systematic risk and hence expected returns through the merger and restructuring events.

\section{Firm-level betas before the takeover}

Consider first the dynamics of firm-level betas before the takeover. As shown in Propositions 1,2 , and 3 , the beta of the shares of the bidder prior to the takeover solves:

$$
\beta_{t}=\beta_{X}+(\vartheta-1)\left(\beta_{X}-\beta_{Y}\right) \frac{O_{B}^{m}(X, Y)}{K_{B} X+O_{B}^{m}(X, Y)}, \quad \text { for } t<\mathcal{T}^{m} .
$$

In this expression, the first term on the right hand side is the beta of assets in place. The second term captures the risk of the option to enter the takeover deal. In this second term, the last factor represents the fraction of firm value accounted for by the option to merge. The elasticity $\vartheta$ of the option price with respect to the underlying asset is strictly greater than 1 for a call option. Thus when $\beta_{Y}=0$, which is the case in standard real options models with a fixed investment cost, the call option always increases the beta of the firm before the option exercise. By contrast, when $\beta_{Y} \neq 0$, which is the case in mergers and acquisitions, the (call) option might increase or decrease beta depending on the relative magnitudes of $\beta_{X}$ and $\beta_{Y}$. In addition, as the takeover becomes more likely, the value of the option to merge increases as a percentage of the total value of the firm. As a result, the impact of the option on beta increases with the moneyness of the option. Interestingly, these results hold independently of the presence of follow-up options or competition. These dimensions of the firm's environment only affect the magnitude of the predicted run-up or run-down. In particular, since follow-up options increase the value of the option to merge while competition erodes this value, the run-up should be greater with more follow-up options and smaller with more competition.

The following Proposition summarizes these results.

Proposition 4 When the beta of the core assets of the acquiring firm is larger (resp. lower) than the beta of the core assets of the target firm, we should observe a run-up (run-down) in firm-level beta prior to the takeover. The magnitude of the pre-merger run-up (run-down) is greater when the firm has follow-up options and lower when there is competition for the target. 
Example. We now turn to a numerical example in which we use the calibrated model parameters reported in Table 1. Figure 1 plots the beta of the shares of bidding shareholders before the takeover as a function of the volatility of core business valuations, the correlation coefficient between these valuations, and the moneyness of the option to merge (ratio of core asset values) when the beta of the bidder's core assets is larger (left panels) or lower (right panels) than the beta of the target's core assets. In this figure, the solid line represents a deal in which there is no competition and no follow-up options. The dotted line considers a deal with follow-up options but without competition. The dashed line considers a deal without follow-up options and with competition.

\section{[Insert Figure 1 Here]}

Figure 1 demonstrates that when $\beta_{Y}$ is low (and possibly equal to zero), the call option to restructure increases firm risk and hence the beta of the shares of bidding shareholders. This is apparent on the left panels of the Figure, in which the shares' beta can be greater than the values of both $\beta_{X}$ and $\beta_{Y}$. In general, when $\beta_{Y} \geq 0$, the impact of the restructuring (call) option depends on the relative magnitudes of $\beta_{X}$ and $\beta_{Y}$. When $\beta_{X}>\beta_{Y}$, a change in input parameter values that increases the likelihood of a restructuring (i.e. the moneyness of the option) increases the beta of the shares of bidding shareholders. When $\beta_{X}<\beta_{Y}$, the reverse is true. Importantly, and as shown in Proposition 4, this analysis implies that we should observe a run-up in the beta of the acquiring firm prior to the takeover when $\beta_{X}>\beta_{Y}$. By contrast we should observe a run-down in the beta of the acquiring firm in transactions for which $\beta_{X}<\beta_{Y}$. These effects are illustrated by Figure 1, which shows the evolution of beta as the ratio $R$ of core business valuations converges to the takeover threshold.

Recall that in our model the moneyness of the option to merge is captured by the distance between the ratio of core asset values and the restructuring threshold. This implies that any change in the firm's environment that leads to an increase in the restructuring threshold reduces the moneyness of the option and hence its impact on firm-level betas. For example, an increase in the volatility or the drift rate of the bidder's core assets leads to an increase in the restructuring threshold and, hence, to a decrease (increase) in the beta of the shares of bidding shareholders when $\beta_{X}>\beta_{Y}$ $\left(\beta_{X}<\beta_{Y}\right)$. By contrast, an increase in the correlation coefficient or in the value of the synergy benefits leads to a decrease in the restructuring threshold and hence to a increase (decrease) in the beta of the shares of bidding shareholders when $\beta_{X}>\beta_{Y}$ $\left(\beta_{X}<\beta_{Y}\right)$. This analysis again illustrates the importance of using a two-factor model that captures the heterogeneity in business risk between bidding and target firm. 


\section{Change in beta at the time of the takeover}

At the time of the takeover, bidding shareholders exercise their option to enter the takeover deal, leading to a change in the nature of the firm's assets and, thus, to a change in the beta of the shares of the acquiring firm. In particular, when there is no follow-up option and no competition, the change in beta at the time of the takeover satisfies (see Proposition 1):

$$
\Delta \beta_{\mathcal{T}^{m}}=\left(\beta_{Y}-\beta_{X}\right)\left[\frac{(1-\alpha) K_{T}}{V\left(R^{m}, 1\right)}+\frac{(\omega+\alpha-1) K_{T}}{V\left(R^{m}, 1\right)-\omega K_{T}}\right] .
$$

This equation shows that the difference in betas of the bidding and target firms has a first order effect on the size of the jump in beta at the time of the takeover. In addition, since the sunk takeover cost $\omega$ is strictly positive, we have the following result.

Proposition 5 When the beta of the core assets of the acquiring firm is larger (resp. lower) than the beta of the core assets of the target firm, we should observe a reduction (increase) in firm-level beta at the time of the takeover.

As we show in the example below, the same holds true when follow-up options and competition are introduced as these dimensions of the firm's environment only affect the magnitude of the change and not its sign.

Example. Figure 2 plots the change in the beta of the shares of bidding shareholders at the time of the takeover as a function of the relative size of the target firm $\left(K_{T} / K_{B}\right)$, the volatility of core business valuations, and the correlation coefficient between these valuations when the beta of the bidder's core assets is larger (left panels) or lower (right panels) than the beta of the target's core assets. In this figure, the solid line represents a deal in which there is no competition and no follow-up options. The dotted line considers a deal with follow-up options but without competition. The dashed line considers a deal without follow-up options and with competition.

\section{[Insert Figure 2 Here]}

Figure 2 demonstrates that exercising a call option leads to a decrease in systematic risk and hence in expected stock returns only when $\beta_{X}>\beta_{Y}$. The figure also reveals that the follow-up options and competition affect the size of the jump but not its sign, as conjectured earlier. Finally, and consistent with the discussion reported in subsection 1 , the size of the jump in betas increases with the relative size of the target firm and the correlation coefficient between core business valuations and decreases with their growth rates and volatilities. It is important to note however that the relative 
size of the target firm has relatively little impact on the size of the jump in betas at the time of the takeover (a similar pattern shows up in the empirical section). Figure 3 summarizes the risk dynamics in mergers and acquisitions through the event time window as captured by an increasing ratio of core assets.

\section{[Insert Figure 3 Here]}

In this figure, the solid line represents a deal without competition and follow-up options. The dotted line considers a deal with follow-up options but without competition. The dashed line considers a deal without follow-up options and with competition.

\section{Change in beta at the time of an option exercise}

To investigate further the impact of the option exercise on the beta of bidding shareholders, we compute the change in betas at the time of the exercise of the operating option. Using the expression reported in Proposition 2, it is possible to show that when there is no option to expand we have for $t \in\left[\mathcal{T}^{m}, \mathcal{T}^{d}\right]$ :

$$
\lim _{R \downarrow R^{d}} \beta_{t}=\frac{v\left(R^{d}, 1\right)+\Pi(\nu)\left[\theta\left(R^{d}+1\right)-(1-\Theta) V\left(R^{d}, 1\right)\right]}{V\left(R^{d}, 1\right)+\left[\theta\left(R^{d}+1\right)-(1-\Theta) V\left(R^{d}, 1\right)\right]},
$$

where the term in the square bracket represent the surplus created by the (put) option to divest assets. Similarly, when there is no option to divest we have for $t \in\left[\mathcal{T}^{m}, \mathcal{T}^{e}\right]$ :

$$
\lim _{R \uparrow R^{e}} \beta_{t}=\frac{v\left(R^{e}, 1\right)+\Pi(\vartheta)\left[(\Lambda-1) V\left(R^{e}, 1\right)-\lambda\left(R^{e}+1\right)\right]}{V\left(R^{e}, 1\right)+\left[(\Lambda-1) V\left(R^{e}, 1\right)-\lambda\left(R^{e}+1\right)\right]}
$$

These equations show that the change in beta depends on whether the option being exercised is a call option to expand operations or a put option to divest assets (this distinction is captured by the factors $\Pi(\vartheta)$ and $\Pi(\nu))$.

Example. Figure 4 plots the change in beta occurring at the exercise date of an operating option as a function of the "exercise price" of the option $(\lambda$ or $\theta)$ and the volatility of participating firms' core business valuations when the firm exercises either an expansion option or a disinvestment option.

\section{[Insert Figure 4 Here]}

Consistent with economic intuition, Figure 4 reveals that the exercise of an operating option triggers a discrete change in the beta of the shares of bidding shareholders. In addition, the sign of the change depends on the nature of the option available to the firm. When $\beta_{Y}=0$, the change is negative in case of an expansion option as the firm 
is exercising a call option. The change is positive in the case of a disinvestment option as the firm is exercising a put option. When $\beta_{Y}>0$, the sign of the change in the beta depends again on the relative magnitudes of $\beta_{X}$ and $\beta_{Y}$. In particular, when $\beta_{X}>\beta_{Y}$ exercising a call reduces the beta of the shares and exercising a put increases the beta of the shares. When $\beta_{Y}>\beta_{X}$ (i.e. the beta of the exercise price exceeds the beta of the underlying asset), the reverse is true.

This analysis again illustrates the impact of the heterogeneity in business risk on the changes in systematic risk following an option exercise decision and hence the importance of using a two-factor model. Notably, it shows that the exercise of an expansion (call) option might not be followed by a decrease in systematic risk if the new project's risk structure is not a carbon copy of existing assets' risk structure. Conversely, the exercise of a put option might not be followed by an increase in systematic risk. Our paper therefore contributes to the literature that examines the long-run performance of firms following acquisitions or divestitures. For example Desai and Jain (1999) report that in their sample of 155 spin-offs from 1975 to 1991, parent firms on average earn positive abnormal returns of $6.5 \%$ to $15.2 \%$ over holding periods of one to three years following substantial divestitures. These results suggest that in their sample we have $\beta_{Y}<\beta_{X}$ (this is the case for example if the selling price of assets is constant). Carlson, Fisher and Giammarino (2005c) also report a significant change in long-run stock market performance as following acquisitions (consistent with a drop in beta), that they explain using a real options model similar to ours.

\section{Empirical evidence}

This section reports exploratory tests of our theory. We first study abnormal announcement returns to confirm that our data exhibit the same general patterns that have been reported previously in the literature: acquiring firms earn low or negative abnormal announcement returns, while target firms earn substantially positive abnormal returns around the announcement date of the takeover. Second, we document a slight drop in acquirers' beta at the announcement of the control transaction for our full sample of takeover deals. If we control for the relative magnitude of acquirers' and targets' betas, the data exhibit a significant increase (decrease) in acquirers' systematic risk prior to the takeover and a significant decrease (increase) thereafter. Third, we provide novel insights into the long-run return dynamics relating pre-merger run-ups and post-merger performance to contrast our theory's predictions with those of a coinsurance effect. The new evidence in this section is strongly supportive of the model's predictions regarding the dynamics of firm-level betas in mergers and acquisitions. 
Our source for identifying control transactions is the Securities Data Company's (SDC) U.S. Mergers \& Acquisitions database. We apply the following filters to a preliminary sample that begins on January 1, 1985, and ends on June 30, 2002: (1) The transaction is completed within less than 700 days (above the 99th percentile of time between the announcement and effective dates in the preliminary sample). (2) The acquirer and the target are public firms listed on the Center for Research in Security Prices (CRSP) database. (3) The transaction value is $\$ 50$ million and higher to limit ourselves to larger takeovers. (4) The percent of shares acquired in the deal is $50 \%$ and higher to focus on significant share acquisitions. (5) All regulated (SICs 4900-4999) and financial (SICs 6000-6999) firms are removed from the sample to avoid restructuring policies governed by regulatory requirements. Transaction value is defined by SDC as the total value of consideration paid by the acquirer, excluding fees and expenses. The SDC database records deals when at least $5 \%$ of shares are acquired. As a result of these selection criteria, our final sample includes 1086 takeovers deals. The sample ends on June 302002 because we will estimate acquirers' betas for event windows of up to two years before the announcement and after the effective date of the control transaction. The average implementation time between announcement and effective dates in our sample is 143 calendar days.

\section{A. Abnormal announcement returns}

The most reliable evidence on whether mergers and acquisitions create value for shareholders draws on short-term event studies [see Andrade, Mitchell, and Stafford (2001) and others]. Most event studies examine abnormal returns around merger announcement dates as an indicator of value creation or destruction. A commonly used event window is the three-day period immediately surrounding the merger announcement date; that is, from one trading day before to one trading day after the announcement.

\begin{tabular}{ccc}
\hline \hline TABLE 2 & ACQUiRER CARS & TARGET CARS \\
\hline \multirow{2}{*}{$-1,+1]$} & $-0.52 \%$ & $18.21 \%$ \\
t-value & -2.26 & 24.97 \\
$N$ & 1086 & 1086 \\
& & \\
\hline \hline
\end{tabular}

Table 2 summarizes our findings on abnormal announcement period returns to shareholders and shows that our data demonstrate the same general patterns that have 
been reported previously in the literature. As in prior studies [see e.g. Bradley, Desai, and Kim (1988)], we cumulate the daily abnormal return from a market model over a three trading day period to obtain the cumulative abnormal return $(C A R)$ for each of the 1086 takeover transactions. Based on a 90 day estimation period prior to the event period, we report the average $C A R \mathrm{~s}$ in Table 2.

Relative to the existing evidence on abnormal announcement returns, our sample firms display similar patterns and economic magnitudes. The returns to shareholders of acquiring firms are slightly negative, reaching $-0.52 \%$ on average, which is perhaps attributable to one of our selection criteria [Moeller, Schlingemann, and Stulz (2004) report lower abnormal announcement period returns for their subsample of larger transactions]. Interestingly, the average abnormal return for acquirers is reliably different from zero. The returns to shareholders of target firms during the three trading day event-window average $18.21 \%$. Target abnormal returns are hence economically large and statistically distinguishable from zero at better than $1 \%$. Finally, we find $C A R \mathrm{~s}$ for acquiring firms are on average equal to $-1.65 \%$ in a subsample of 39 deals with multiple bidders, which is consistent with the predictions of Proposition 3 and Appendix D.

[Insert Figure 5 Here]

To complete the event-window return analysis, Figure 5 details the frequency distributions of cumulative abnormal announcement returns to bidding and target shareholders.

\section{B. Beta dynamics}

We now investigate whether the dynamics of firm-level betas in the time period surrounding the announcement is consistent with our model's predictions. To this end, we examine how an average bidding firm's systematic risk varies through the event window surrounding a control transaction. Following Carlson, Fisher and Giammarino (2005c), we divide our sample into twenty-one trading day periods ("event months") prior to the announcement and after the takeover. We consider as a single period ("event month zero") the interval between the announcement and the takeover, regardless of how long that interval is. As a result, every event month corresponds to 21 trading days except for event month zero, which equals on average of 103 trading days for our sample.

Following the high-frequency or "realized beta" approach of Andersen, Bollerslev, Diebold, and $\mathrm{Wu}$ (2005), we estimate monthly betas from daily data. We obtain daily data of the relevant factors, prices, and returns from WRDS. In particular, the daily time-series of risk-free interest rates and excess index returns from 1985 to 2002 correspond to one-month Treasury Bill rates (RF) and valued-weighted excess market returns (MKTRF). For each event month, we estimate linear regressions of daily stock 
returns on daily excess market returns and hence we obtain monthly estimates of each stock's alpha and beta according to the market model. ${ }^{7}$ The term "realized betas" is used because of the analogy with "realized volatility" calculated from high frequency observations [see e.g. Schwert (1989)].

Figure 6a displays average monthly beta estimates for the time period surrounding the announcement date of the control transaction. In this graph, the value of zero on the horizontal axis corresponds to the announcement date. All negative numbers are event months prior to the announcement. All positive numbers are event months after the effective date. Event month zero is the period ranging from the announcement date to the effective date irrespective of the actual time elapsed. Our analysis in Section IV predicts an increase (run-up) in acquirers' systematic risk before the announcement and a decrease thereafter so long as $\beta_{X}>\beta_{Y}$. Figure 6a reveals that betas do not vary substantially around takeover announcements for the full sample of takeover deals. Although the average acquiring firm's beta $\left(\bar{\beta}_{A c q}=1.04\right)$ is greater than the average target firm's beta $\left(\bar{\beta}_{\text {Tar }}=0.84\right)$ for all 1086 transactions, the increase of beta before the announcement is not distinguishable from other fluctuations. However, the decrease of beta in event month zero appears to be present in the data for the full sample. In addition to the five-month period labeled 0 , this decrease in beta lasts for two event months after the effective date of the control transaction.

\section{[Insert Figure 6 Here]}

We attribute this relatively weak support of our model in the full sample to the fact that the cross-sectional variation in $\beta_{X}$ and $\beta_{Y}$ is too large to have sufficient identification. Notably, the standard deviations of acquirers' and targets' pre-announcement betas are around 0.80 . We therefore split our sample based on the relative magnitude of pre-announcement betas to obtain a subsample for which $\beta_{X}>\beta_{Y}$ and a subsample for which $\beta_{X}<\beta_{Y} \cdot{ }^{8}$ Figures $6 \mathrm{~b}$ and $6 \mathrm{c}$ show acquirers' beta dynamics when $\beta_{X}>\beta_{Y}$ (641 deals) and when $\beta_{X}<\beta_{Y}$ (445 deals), respectively. Consistent with our model's predictions, we record an increase (run-up) in beta in the last months prior to the announcement date where the acquirers' average beta rises from 1.16 up to 1.30. Due to the option exercise decision, the acquirers' average beta drops dramatically upon announcement of the takeover. Our estimate for beta equals 1.09 during event month

\footnotetext{
${ }^{7}$ In unreported estimations, we run linear CAPM-like regression of daily excess stock returns on daily excess market returns without an intercept term. Restricting the intercept to be equal to the risk-free rate $(\mathrm{RF})$ does not produce qualitatively different results.

${ }^{8}$ Simple computations show that if $\beta_{X}>\beta_{Y}$, then the beta of the acquiring firm is greater than the beta of the target firm (see Appendix C). For the two subsamples, the average acquiring firm's beta $\bar{\beta}_{A c q}=1.28\left(\bar{\beta}_{A c q}=0.69\right)$ differs from the average target firm's beta $\bar{\beta}_{\text {Tar }}=0.60\left(\bar{\beta}_{\text {Tar }}=1.22\right)$.
} 
zero, which corresponds to 103 trading days on average. Thus, as predicted by our theory, acquirers' beta first rises slowly and then declines abruptly for the subsample of deals with $\beta_{X}>\beta_{Y}$ in Figure 6b.

For the subsample of deals with $\beta_{X}<\beta_{Y}$, we observe the reverse phenomenon in Figure 6c. Beta begins to drop below its unconditional time-series average of 0.95 around 12 months before the announcement (run-down). During the last months prior to announcement, the acquirers' average beta declines considerably from about 0.85 down to 0.67 . At the announcement date, acquirers' average beta rises dramatically because of the option exercise. Specifically, the acquirers' average beta jumps up from 0.67 to 0.94 in event month zero, which equals almost five calendar months on average. Thus, as predicted by our theory, beta first declines slowly and then rises abruptly upon announcement for the subsample of deals with $\beta_{X}<\beta_{Y}$ in Figure 6c.

\section{[Insert Figure 7 Here]}

A potentially important concern regarding the quantitative underpinnings of this pattern may be related to systematic changes in the acquiring firm's stock liquidity. In particular, if beta estimates are biased due to the omission of liquidity-related variables, changes in liquidity conditions through the merger episode that affect such a bias could produce apparent changes in beta. To examine this possibility, we use various measures of liquidity. ${ }^{9}$ Using daily return and volume observations, Pastor and Stambaugh (2003) consider the regression coefficient $\hat{\gamma}_{i t}$ of the linear model $r_{i t}^{e}=\theta_{i t}+\phi_{i t} r_{i t}+\gamma_{i t} \operatorname{sign}\left(r_{i t}^{e}\right)$. $v_{i t}+\epsilon_{i t}$, where $r_{i t}^{e}=r_{i t}-r_{f t}$ and $v_{i t}$ denote excess stock return and dollar volume of stock $i$ in month $t$. The coefficient estimate for gamma is a liquidity measure as volume-related return reversals tend to arise from liquidity effects. We thus stratify our two samples into "high", "medium", and "low" liquidity categories to investigate whether systematic differences in stock liquidity through the merger episode explain changes in systematic risk. These tests are summarized in Figure 7, which shows no evidence in favor of a liquidity-induced pattern in firm-level beta dynamics.

\section{[Insert Figure 8 Here]}

The dynamics of firm-level betas can be studied further by relating run-ups and rundowns in betas to firm-level variables such as the relative size of acquirers and targets capital stocks ( $K_{B}$ and $K_{T}$ in our model). We therefore construct the variable KBKT, which equals the logarithm of the acquirer's divided by the target's total assets at the

\footnotetext{
${ }^{9}$ In unreported tests, we have not found a liquidity effect when considering subsamples based on share trading volume (rather than dollar volume). Specifically, we divided our sample into three liquidity groups based on (1) three-month averages of pre-announcement trading volume and (2) summed up changes in trading volume over the three month period prior to the announcement date.
} 
year-end preceding the announcement. We then re-examine the dynamics of firm-level betas in the full sample as well as in the two subsamples $\beta_{X}>\beta_{Y}$ and $\beta_{X}<\beta_{Y}$. As charted in Figure 8, we break up each sample based on the median value of KBKT into "high" and "low" relative size sub-groups. The analysis reveals that the asymmetry of the model is also apparent in the data where the relative size in the jump in beta is bigger for lower values of KBKT. ${ }^{10}$

\section{Return dynamics and beta changes}

In this subsection, we examine whether long-run post-merger returns and firm-level betas are related to pre-merger run-ups. In our model, more uncertainty regarding synergy benefits leads to a lower run-up in beta as the exercise of the restructuring option can not be anticipated by investors. As noted by Carlson, Fisher, and Giammarino (2005c), since the difference between pre-announcement and post-announcement returns also reflects anticipation, post-merger performance relates to run-ups and announcement effects. For example, smaller run-ups and larger announcement effects should be associated with less underperformance and a smaller decrease in beta (see also Figure 3). While a coinsurance (diversification) effect may explain post-merger underperformance, this alternative hypothesis is silent on run-ups (or run-downs) in stock price and beta before the takeover announcement. We therefore argue that the predicted relation between run-ups and post-merger performance distinguishes our theory from an explanation of post-merger performance based on the coinsurance effect.

\section{[Insert Table 3 Here]}

In Table 3, we first report estimation results for cumulative abnormal returns $(C A R \mathrm{~s})$ from one and two year periods following the effective date of mergers. For each firm, we determine normal returns using the market model $r_{i t}=\alpha_{i}+\beta_{i} r_{m t}+\epsilon_{i t}$ and compute $C A R_{i t}$ of firm $i$ on trading day $t$ as $C A R_{i t}=\sum_{j=1}^{t}\left(r_{i j}-\hat{\alpha}_{i}-\hat{\beta}_{i} r_{m j}\right)$, where $t=252$ for CAR1 and $t=504$ for CAR2. We regress CAR1 and CAR2 against the one year run-up in the acquirer's stock price (RUNUP1), the relative size of acquirers and targets (KBKT), and the relative pre-announcement risk of acquirers and targets (RISK). We add several control variables by relying on data from Compustat and SDC. We include for the announcement effect the three-day $C A R \mathrm{~s}(\mathrm{~A} / \mathrm{E})$ from Section V.A, the book-to-market ratio in the year prior to the takeover $(B / M)$, the deal value as a percentage of the acquiring firm's market value of equity $(D / M)$, the run-up in the market portfolio one year prior to the announcement (MKT), the percentage of shares

\footnotetext{
${ }^{10}$ When we specify relative size by book value or market value of equity at the fiscal year-end preceding the announcement date, the results display the same asymmetry as in Figure 8 .
} 
acquired in the control transaction (PCACQ), the logarithm of total assets in the year prior to the takeover (SIZE), and an intercept term.

A few results stand out in columns (1) and (2). First, the one year run-up is negative and significant with a t-statistic of 7.79 (8.45) for CAR1 (CAR2). ${ }^{11}$ Thus, higher run-ups prior to the takeover announcement lead to more underperformance in the following two years. In addition, a few other regressors help explain post-merger $C A R$ s. Larger deals as percentage of acquiring firms' equity value experience reliably lower post-merger performance. Also, the negative coefficient estimates for relative risk is statistically significant. This finding directly implies that post-merger performance is lower (higher) when the pre-merger risk differential is higher (lower). Though not statistically significant, smaller acquirers and larger percentages of acquired shares lead to lower $C A R$ s. Overall, the negative relation between pre-merger risk, pre-merger runups and post-merger performance is in line with our theory's predictions, and cannot be explained by a coinsurance effect.

In specifications (3)-(8), we study the determinants of changes in betas of acquiring firms, defined as the difference in systematic risk between the six month window following the merger announcement and the three month window preceding its announcement. ${ }^{12}$ As discussed earlier, we expect the sign of RUNUP1 to be negative, so that firms with larger run-ups have larger changes in beta at the deal announcement. For specifications (3)-(5), we include the same regressors as in columns (1)-(2). The coefficient estimate of the one year price run-up is negative, as expected, and significant in the full sample. It is, however, of particular importance for the subsample regression (4) in which acquirer betas exceeds target betas. The weaker statistical relation between $\Delta \beta_{\mathcal{T}^{m}}$ and RUNUP1 in column (5) is potentially due to insufficient crosssectional variation in the two subsamples; that is, RUNUP1 is less positive relative to the subsample in column (4) but it is not negative in the sense of a run-down. A higher percentage of shares acquired (PCACQ) and higher pre-merger risk-differential reliably predict higher changes in beta. Finally, these regressions reveal that the change in beta at the announcement date is negatively related to the size of the acquiring firm (SIZE).

We next examine the impact RUNUP2, which equals the one year change in the bidder's beta (rather than stock price) preceding the announcement date, on the jump in beta at the time of the takeover in columns (6)-(8). This experiment allows us to separate our model's implications for post-merger performance from the ones based on the coinsurance effect. All other variable definitions remain unchanged. The regression coefficient corresponding to RUNUP2 in Table 3 is negative and statistically significant

\footnotetext{
${ }^{11}$ All t-statistics are computed using White standard errors.

${ }^{12}$ Unreported regressions for different specifications of the post-merger estimation window of firmlevel beta yield qualitatively and quantitatively very similar results.
} 
at better than $0.1 \%$. This means economically that for $\beta_{X}>\beta_{Y}$ a run-up in beta from 0.75 to 1.25 before the merger (i.e. RUNUP2 $=+0.5$ ) leads, on average, to a decrease in beta of $\Delta \beta_{\mathcal{T}^{m}}=(1.25-0.75)(-0.296)=-0.148$. On the other hand, an equivalent run-down in the acquirer's beta (i.e. RUNUP2 $=-0.5)$ results for $\beta_{X}<\beta_{Y}$, on average, in an increase in beta of $\Delta \beta_{\mathcal{T}^{m}}=(0.75-1.25)(-0.231)=0.116$ at the time of the takeover.

The table also reveals that the three-day announcement return and relative size are marginally significant, while relative risk remains an important determinant of changes in beta. Acquirer size enters with the predicted sign (a greater size of the bidder leads to a smaller jump), but the statistical relation is weak. The deal value as a percentage of the acquiring firm's market value of equity $(D / M)$ is another interesting control variable in all specifications. The negative (positive) coefficient estimate corresponding to $\mathrm{D} / \mathrm{M}$ implies that, everything else equal, a larger fraction of deal value relative to equity value leads to a larger change in beta. This finding is consistent with our real options framework in that the moneyness factor $\Gamma$, which represents the fraction of firm value accounted for by the option to merge, should be increasing in $\mathrm{D} / \mathrm{M}$.

\section{Conclusions}

This paper develops a real options framework to analyze the dynamics of stock returns and firm-level betas in mergers and acquisitions. In this framework, the timing and terms of takeovers are endogenous and result from value-maximizing decisions. The implications of the model for abnormal announcement returns are consistent with the empirical evidence. In addition, the model generates new predictions regarding the dynamics of firm-level betas for the time period surrounding control transactions. In particular, the model predicts a run-up (run-down) in the beta of the bidding firm prior to the announcement and a drop (rise) in beta at the time of the announcement when the acquiring firm has a higher (lower) pre-announcement beta than its target.

Using a sample of 1086 takeovers of publicly traded US firms between 1985 and 2002 , we find that beta does not exhibit any significant change prior to the takeover and drops only moderately after a merger announcement for the full sample. However, if we split our sample into two subgroups in which acquiring firms have either a higher or a lower pre-announcement beta compared to their targets, the patterns in the beta of acquiring firms are consistent with the model's predictions. Specifically, beta first increases and then declines upon announcement for the subsample of deals in which the beta of the bidder exceeds the beta of the target. Beta first declines and then rises upon announcement for the other subsample of deals. This new evidence on the dynamics of firm-level betas is strongly supportive of the model's predictions. 


\section{Appendix}

\section{A. Proof of proposition 1, 2, and 3}

Denote the value of the bidder's restructuring option by $O^{B}(X, Y)$. In the region for the two state variables where there is no takeover, this option value satisfies

$r O^{B}=\left(r-\delta_{X}\right) X O_{X}^{B}+\left(r-\delta_{Y}\right) Y O_{Y}^{B}+\frac{1}{2} \sigma_{X X}^{2} X^{2} O_{X X}^{B}+\rho \sigma_{X} \sigma_{Y} X Y O_{X Y}^{B}+\frac{1}{2} \sigma_{Y}^{2} Y^{2} O_{Y Y}^{B}$

The value function $O^{B}(X, Y)$ is linearly homogeneous in $X$ and $Y$. Thus, the optimal restructuring policy can be described using the ratio of the two stock prices: $R=X / Y$. Also, the value of the restructuring option can be written as

$$
O^{B}(X, Y)=Y O^{B}(X / Y, 1)=Y O^{B}(R) .
$$

Successive differentiation gives

$$
\begin{aligned}
O_{X}^{B}(X, Y) & =O_{R}^{B}(R), \\
O_{Y}^{B}(X, Y) & =O^{B}(R)-R O_{R}^{B}(R), \\
O_{X X}^{B}(X, Y) & =O_{R R}^{B}(R) / Y, \\
O_{X Y}^{B}(X, Y) & =-R O_{R R}^{B}(R) / Y, \\
O_{Y Y}^{B}(X, Y) & =R^{2} O_{R R}^{B}(R) / Y .
\end{aligned}
$$

Substituting (A.3)-(A.8) in the partial differential equation (A.2) yields the ordinary differential equation

$$
\delta_{Y} O^{B}(R)=\left(\delta_{Y}-\delta_{X}\right) R O_{R}^{B}(R)+\frac{1}{2}\left(\sigma_{X X}^{2}-2 \rho \sigma_{X} \sigma_{Y}+\sigma_{Y}^{2}\right) R^{2} O_{R}^{B}(R),
$$

which is solved subject to the the value-matching and smooth-pasting conditions

$$
\begin{aligned}
& O^{B}\left(R_{B}^{m}\right)=\xi\left[V\left(R_{B}^{m}, 1\right)-\omega K_{T}\right]-K_{B} R_{B}^{m}, \\
& O_{R}^{B}\left(R_{B}^{m}\right)=\xi V_{R}\left(R_{B}^{m}, 1\right)-K_{B},
\end{aligned}
$$

as well as the no-bubbles condition $\lim _{R \rightarrow 0} O^{B}(R)=0$. The general solution to (A.9) is given by

$$
O^{B}(R)=A R^{\vartheta}+B R^{\nu}
$$

where $\vartheta>1$ and $\nu<0$ the positive and negative roots of the quadratic equation:

$$
\frac{1}{2}\left(\sigma_{X}^{2}-2 \rho \sigma_{X} \sigma_{Y}+\sigma_{Y}^{2}\right)(\vartheta-1) \vartheta+\left(\delta_{Y}-\delta_{X}\right) \vartheta=\delta_{Y}
$$


Condition (A.12) implies that $B=0$. Using conditions (A.10) and (A.11) it is immediate to establish that

$$
O_{B}^{m}(X, Y)=Y\left\{\xi\left[V\left(R_{B}^{m}, 1\right)-\omega K_{T}\right]-K_{B} R_{B}^{m}\right\}\left(\frac{R}{R_{B}^{m}}\right)^{\vartheta}
$$

where the value-maximizing merger threshold threshold satisfies

$$
R_{B}^{m}=\frac{\vartheta}{\vartheta-1} \frac{\xi(\alpha+\omega-1) K_{T}}{(\xi-1) K_{B}+\xi \alpha K_{T}} .
$$

Consider next the option to merge for target shareholders. Using the same steps as above we find

$$
O_{T}^{m}(X, Y)=Y\left\{(1-\xi)\left[V\left(R_{T}^{m}, 1\right)-\omega K_{T}\right]-K_{T}\right\}\left(\frac{R}{R_{T}^{m}}\right)^{\vartheta}
$$

where the merger thresholds selected by bidding and target shareholders satisfy

$$
R_{T}^{m}=\frac{\vartheta}{\vartheta-1} \frac{[\xi(\alpha+\omega-1)-(\omega+\alpha)] K_{T}}{(\xi-1)\left(K_{B}+\alpha K_{T}\right)} .
$$

The equality $R_{B}^{m}\left(\alpha_{k}\right)=R_{T}^{m}\left(\alpha_{k}\right)$ then gives the sharing rule ${ }^{13}$

$$
\xi=\frac{(\omega+\alpha) K_{B}}{(\omega+\alpha) K_{B}+\alpha K_{T}}
$$

and the merger threshold

$$
R^{m}=\frac{\vartheta}{\vartheta-1} \frac{\omega+\alpha}{\alpha} .
$$

One interesting feature of the equilibrium described in Proposition 1 is that it can be formulated as a surplus-maximization problem for a central planner. The objective of the planner is to determine the restructuring policy that maximizes the combined surplus

$$
G(X, Y)=Y K_{T}[\alpha R-(\alpha+\omega)] .
$$

Using similar arguments as above, it is possible to show that the surplus-maximizing policy is identical to the restructuring policy described in Proposition 1. This feature is useful to establish the merger threshold reported in Proposition 2.

\footnotetext{
${ }^{13}$ When the implementation cost is fully paid by the bidder, the sharing rule for the combined firm is

$$
\xi=\frac{\omega\left(K_{B}+\alpha K_{T}\right)+\alpha K_{B}}{(\alpha+\omega) K_{B}+(1+\omega) \alpha K_{T}} .
$$

and the Nash-equilibrium merger threshold is given as in equation (A.18).
} 
The main difference between Proposition 1 and Proposition 2 is that one has to derive first the expansion and disinvestment thresholds $R^{e}$ and $R^{d}$ as well as the value of the follow-up options. Denote by $O^{c}(X, Y)$ the combined value of the real option to expand and the real option to divest assets. The thresholds $R^{e}$ and $R^{d}$ can then be determined using the value-matching and smooth-pasting conditions:

$$
\begin{aligned}
O^{c}\left(R^{e}, 1\right) & =(\Lambda-1) V\left(R^{e}, 1\right)-\lambda\left(R^{e}+1\right), \\
O^{c}\left(R^{d}, 1\right) & =\theta\left(R^{d}+1\right)-(1-\Theta) V\left(R^{d}, 1\right), \\
O_{R}^{c}\left(R^{e}, 1\right) & =(\Lambda-1) V_{R}\left(R^{e}, 1\right)-\lambda, \\
O_{R}^{c}\left(R^{d}, 1\right) & =\theta-(1-\Theta) V_{R}\left(R^{d}, 1\right)
\end{aligned}
$$

Simple algebraic manipulations yield the desired result.

Denote by $S(X, Y)$ the value of bidding shareholders' claims. By a straightforward application of Itô's lemma, it is immediate that an investment in $X S_{X}(X, Y) / S(X, Y)$ units of $X$ and $Y S_{Y}(X, Y) / S(X, Y)$ units of $Y$ instantaneously replicates firm value. As a result, we obtain the beta of the shares of bidding shareholders as a weighted average of the elasticities of $S(X, Y)$ with respect to $X$ and $Y$,

$$
\beta=\left[X \beta_{X} S_{X}(X, Y)+Y \beta_{Y} S_{Y}(X, Y)\right] / S(X, Y) .
$$

Since the functional form of $S(X, Y)$ changes through the merger event, so does that of the beta of the shares of bidding shareholders. Simple algebraic derivations yield the analytic expressions reported in Propositions 1, 2, and 3.

\section{B. Proof of proposition 4}

As shown in equation (12), the beta of the shares of the bidding firm prior to the takeover is given by:

$$
\beta_{t}=\beta_{X}+(\vartheta-1)\left(\beta_{X}-\beta_{Y}\right) \Gamma(R, 1)
$$

where the factor $\Gamma(X, Y)$ represents the fraction of firm value accounted for by the option to merge defined by:

$$
\Gamma(R, 1)=\frac{O_{B}^{m}(R, 1)}{K_{B} R+O_{B}^{m}(R, 1)} .
$$

Since the takeover occurs the first time the process $R$ reaches the constant threshold $R^{m}$ from below, we should observe a run-up in $R$ prior to the takeover. In addition, in this expression the elasticity $\vartheta$ is greater than one. This implies that if $\partial \Gamma / \partial R>0$, 
then we should observe a run-up in beta prior to the takeover when $\beta_{X}>\beta_{Y}$. Simple calculations give

$$
\frac{\partial \Gamma(R, 1)}{\partial R}=\frac{(\vartheta-1) K_{B} O_{B}^{m}(R, 1)}{\left[K_{B} R+O_{B}^{m}(R, 1)\right]^{2}}>0,
$$

which yields the result in Proposition 4.

\section{Subsample selection}

In this appendix, our aim is to show that if $\beta_{X}>\beta_{Y}$, then the beta of the acquiring firm is greater than the beta of the target firm. In our base case environment, the betas of the shares of the bidding and target firm satisfy

$$
\beta_{A c q}=\beta_{X}+\left(\beta_{X}-\beta_{Y}\right) \frac{(\vartheta-1)\left\{\xi\left[V\left(R^{m}, 1\right)-\omega K_{T}\right]-K_{B} R_{B}^{m}\right\} R^{\vartheta}\left(R^{m}\right)^{-\vartheta}}{K_{B} R+\left\{\xi\left[V\left(R^{m}, 1\right)-\omega K_{T}\right]-K_{B} R_{B}^{m}\right\} R^{\vartheta}\left(R^{m}\right)^{-\vartheta}}
$$

and

$$
\beta_{\text {Tar }}=\beta_{Y}+\left(\beta_{X}-\beta_{Y}\right) \frac{(\vartheta-1)\left\{(1-\xi)\left[V\left(R^{m}, 1\right)-\omega K_{T}\right]-K_{B} R_{B}^{m}\right\} R^{\vartheta}\left(R^{m}\right)^{-\vartheta}}{K_{T}+\left\{(1-\xi)\left[V\left(R^{m}, 1\right)-\omega K_{T}\right]-K_{B} R_{B}^{m}\right\} R^{\vartheta}\left(R^{m}\right)^{-\vartheta}}
$$

so that $\beta_{A c q}-\beta_{\text {Tar }}$ is equal to $\beta_{X}-\beta_{Y}$ when $R$ tends to zero and decreases with $R$. The lowest possible value for $\beta_{A c q}-\beta_{\text {Tar }}$ is reached when $R=R^{m}$. Thus, the lowest possible value for $\beta_{A c q}-\beta_{T a r}$ is given by

$$
\beta_{\text {Acq }}-\beta_{\text {Tar }}=\left(\beta_{X}-\beta_{Y}\right)\left\{1-\frac{(\omega+\alpha) K_{B}}{\alpha\left[V\left(R^{m}, 1\right)-\omega K_{T}\right]}\right\},
$$

which reduces to

$$
\beta_{A c q}-\beta_{T a r}=\left(\beta_{X}-\beta_{Y}\right) \frac{\left(K_{B}+\alpha K_{T}\right)(\omega+\alpha)+(\vartheta-1) \alpha K_{T}}{K_{B}(\vartheta-1)(\omega+\alpha)+\left(K_{B}+\alpha K_{T}\right)(\omega+\alpha)+(\vartheta-1) \alpha K_{T}},
$$

Since $\vartheta>1$ and $(\alpha, \omega) \in \mathbb{R}_{++}^{2}$, the second term on the right hand side is positive and less than one. It follows that $\operatorname{Sign}\left(\beta_{A c q}-\beta_{T a r}\right)=\operatorname{Sign}\left(\beta_{X}-\beta_{Y}\right)$ when $R=R^{m}$.

\section{Abnormal announcement returns}

In our model, abnormal returns are equal to the unexpected component of the surplus accruing to shareholders divided by shareholder value at the time of the takeover. When there is competition for the target and asymmetric information, abnormal announcement returns arise for two reasons. First, market participants have incomplete 
information regarding the takeover surplus. Second, in the case of multiple bidders, market participants typically cannot identify the winning bidder before the takeover announcement. At the time of the takeover announcement, uncertainty is resolved by observing the value of the trigger threshold $R^{*}(\alpha)$ and the equilibrium allocation of the surplus $\xi$.

Example Assume that there are no operating options and that the prior distributions of $\alpha_{1}$ and $\alpha_{2}$ for outside stockholders are uniform with respective sample spaces $\{0.6,1,1.4\}$ and $\{0.95-\eta ; 0.95 ; 0.95+\eta\}$, with $\eta \in(0.05,0.40)$. Denote by $R_{1}^{*}$ the equilibrium takeover threshold when $\left(\alpha_{1} ; \alpha_{2}\right)=(1 ; 0.95)$ and by $R_{2}^{*}$ the equilibrium takeover threshold when $\left(\alpha_{1} ; \alpha_{2}\right)=(1 ; 0.95-\eta)$. At the time of the takeover, the market learns that the true values of $\alpha_{1}$ and $\alpha_{2}$ are respectively 1 and 0.95 so that the value of the shares of the winning bidder becomes (using $Y$ as numéraire):

$$
\begin{aligned}
\xi S^{i}\left(R^{*}, 1\right) & =R_{1}^{*} K_{B}+\left(\alpha_{1, k}-\alpha_{2, k}\right) K_{T}\left(R_{1}^{*}-1\right) \\
& =R_{1}^{*} K_{B}+0.05 K_{T}\left(R_{1}^{*}-1\right) .
\end{aligned}
$$

Just before the announcement of the takeover, the market believes that bidder 1 will win the takeover contest if $\alpha_{1}=1$ (with probability $1 / 2$ ). Two scenarios are then possible: $\left(\alpha_{1} ; \alpha_{2}\right)=(1 ; 0.95)$ with probability $1 / 4$ and $\left(\alpha_{1} ; \alpha_{2}\right)=(1 ; 0.95-\eta)$ with probability $1 / 4$. Hence, the value of the shares of the winning bidder just after the takeover announcement satisfies (using $Y$ as numéraire):

$$
\begin{aligned}
S_{B}^{1}\left(R_{1}^{*}, 1\right) & \left.=R_{1}^{*} K_{B}+\mathbb{E}_{\mathcal{Q}}\left[1_{\alpha_{1}>\alpha_{2}} O_{B i}^{m}(R, 1) \mid \mathcal{F}_{\mathcal{T}_{-}^{m}}\right], 1\right) \\
& =R_{1}^{*} K_{B}+\frac{0.05}{4} K_{T}\left(R_{1}^{*}-1\right)+\frac{0.05+\eta}{4} K_{T}\left(R_{2}^{*}-1\right)\left(\frac{R_{1}^{*}}{R_{2}^{*}}\right)^{\vartheta} .
\end{aligned}
$$

Abnormal returns to bidding shareholders at the time of the takeover announcement are defined as:

$$
A R_{B}=\frac{1}{S_{B}^{1}\left(R^{*}, 1\right)}\left[\xi S^{i}\left(R^{*}, 1\right)-S_{B}^{1}\left(R^{*}, 1\right)\right] .
$$

Using these expressions, it is immediate to establish that abnormal announcement returns to bidding shareholders are negative whenever

$$
\eta>0.15 \frac{R_{1}^{*}-1}{R_{2}^{*}-1}\left(\frac{R_{1}^{*}}{R_{2}^{*}}\right)^{-\vartheta}-0.05
$$

These equations show that takeover deals can entail either positive or negative returns to the winning bidder. The sign of the returns depends on the difference in true synergy parameters. For example, if the two bidders are identical, uncertainty in market beliefs always generates negative abnormal announcement returns. Indeed, in 
this case a bidder's option to merge is worthless. However, the market's expectation of this option is positive. In general, when there is little heterogeneity among bidders, bidders compete most of the rents associated with the merger away. If the uncertainty in market beliefs is high, then the market's expectation of the merger benefits might exceed its true value. Therefore, the market overestimates the benefits of the merger and we observe negative abnormal announcement returns for bidding shareholders. 


\section{References}

Andersen, T., T. Bollerslev, F. Diebold, and J. Wu, 2005, "Realized beta: Persistence and predictability," in T. Fomby and D. Terrell, eds., Advances in Econometrics: Econometric Analysis of Economic and Financial Time Series in Honor of R.F. Engle and C.W.J. Granger, Volume B, pp. 1-40, New York: Elsevier.

Andrade, G., and E. Stafford, 2004, "Investigating the economic role of mergers," Journal of Corporate Finance 10, 1-36.

Andrade, G., M. Mitchell, and E. Stafford, 2001, "New evidence and perspectives on mergers," Journal of Economic Perspectives 15, 103-120.

Berk, J., R. Green, and V. Naik, 1999, "Optimal investment, growth options, and security returns," Journal of Finance 54, 1553-1607.

Bradley, M., Desai, A., and E. H. Kim, 1988, "Synergistic gains from corporate acquisitions and their division between the stockholders of target and acquiring firms," Journal of Financial Economics 21, 3-40.

Carlson, M., A. Fisher, and R. Giammarino, 2005a, "Corporate investment and asset price dynamics: Implications for the cross-section of returns," Journal of Finance 59, 2577-2603.

Carlson, M., A. Fisher, and R. Giammarino, 2005b, "Corporate investment and asset price dynamics: Implications for SEO event studies and long-run performance," Forthcoming Journal of Finance.

Carlson, M., A. Fisher, and R. Giammarino, 2005c, "SEOs, real options, and risk dynamics: Empirical evidence," Working Paper, University of British Columbia.

Cooper, I., 2005, "Asset pricing implications of non-convex adjustment costs and irreversibility of investment," Forthcoming Journal of Finance.

De, S., M. Fedenia, and A. Triantis, 1996, "Effects of competition on bidder returns," Journal of Corporate Finance 2, 261-282.

Desai, H., and P. Jain, 1999, "Firm performance and focus: long-run stock market performance following spinoffs," Journal of Financial Economics 54, 75-101.

Grenadier, S., 2002, "Option exercise games: An application to the equilibrium investment strategies of firms," Review of Financial Studies 15, 691-721.

Ibbotson Associates, 2002, Stocks, Bonds, Bills, and Inflation, 2002 Yearbook.

Jensen, M., and W. Meckling, 1992, "Specific and general knowledge, and organizational structure," in L. Werin and H. Wijkander, eds., Main Currents in Contract Economics, pp. 251-274, Oxford: Blackwell Press. 
Lambrecht, B., 2004, "The timing and terms of mergers motivated by economies of scale," Journal of Financial Economics 72, 41-62.

Lambrecht, B., and S. Myers, 2005, "A theory of takeovers and disinvestment," Forthcoming Journal of Finance.

Lambrecht, B., and S. Myers, 2006, "Debt and managerial rents in a real-options model of the firm," Working Paper, University of Lancaster.

Lang, L., A. Poulsen, and R. Stulz, 1995, "Asset sales, firm performance, and the agency costs of managerial discretion," Journal of Financial Economics 37, 3-37.

Lang, L., R. Stulz, and R. Walking, 1989, "Managerial performance, Tobin's q and the gains from successful tender offers," Journal of Financial Economics 24, 137-154.

Maksimovic, V., and G. Phillips, 2001, "The market for corporate assets: Who engages in mergers and asset sales and are there efficiency gains?" Journal of Finance 56, 2019-2065.

Margrabe, W., 1978, "The value of the option to exchange one asset for another," Journal of Finance 33, 177-186.

Margsiri, W., A. Mello, and M. Ruckes, "A dynamic analysis of growth via acquisitions," Working Paper, University of Wisconsin, Madison.

Morellec, E., 2004, "Can managerial discretion explain observed leverage ratios?" Review of Financial Studies 17, 257-294.

Morellec, E., and A. Zhdanov, 2005, "The dynamics of mergers and acquisitions," Journal of Financial Economics 77, 649-672.

Moeller, S., F. Schlingemann, and R. Stulz, 2004, "Firm size and the gains from acquisitions," Journal of Financial Economics 73, 201-228.

Pastor, L., and R. Stambaugh, 2003, "Liquidity risk and expected stock returns," Journal of Political Economy 111, 642-685.

Schwert, W., 2000, "Hostility in takeovers: In the eyes of the beholder," Journal of Finance 55, 2599-2640.

Schwert, W., 1989, "Why does stock market volatility change over time," Journal of Finance 44, 1115-1153.

Stein, J., 2002, "Information production and capital allocation: Decentralized versus hierarchical firms," Journal of Finance 57, 1891-1921.

Strebulaev, I., 2006, "Do tests of capital structure mean what they say?," Forthcoming Journal of Finance.

Zhang, L., 2005, "The value premium," Journal of Finance 60, 67-103. 
Table 3: Return dynamics and beta changes. Columns (1)-(2) provide estimation results for the $C A R \mathrm{~s}$ from a one and two year period following the effective date of the merger. Columns (3)-(8) analyze the change in betas of acquiring firms, defined as the difference in their betas between the six month window following the announcement date and the three month window preceding the announcement date. RUNUP1 (RUNUP2) is the one year run-up in the acquiring firms' stock price (beta). Other variables include the three day announcement effect $(\mathrm{A} / \mathrm{E})$, the book-to-market ratio at the year-end preceding the announcement $(\mathrm{B} / \mathrm{M})$, the deal-to-market value ratio $(\mathrm{D} / \mathrm{M})$, the logarithm of the ratio of acquirer to target total assets (KBKT), the one year run-up in the value-weighted market portfolio (MKT), the percent of shares acquired (PCACQ), the relative pre-annoucment risk of acquirers and targets (RISK), and the logarithm of the acquirer's total asset at the year-end before the announcement (SIZE). All t-statistics [in brackets] are based on robust standard errors.

\begin{tabular}{|c|c|c|c|c|c|c|c|c|}
\hline \multirow[b]{3}{*}{ Regressor: } & \multicolumn{2}{|c|}{$C A R \mathrm{~s}:$} & \multicolumn{6}{|c|}{ Changes in Beta $\left(\Delta \beta_{\mathcal{T}^{m}}\right)$ : } \\
\hline & (1) & (2) & (3) & (4) & (5) & (6) & (7) & (8) \\
\hline & 1 Year & 2 Years & All & $\underline{\beta_{X}>\beta_{Y}}$ & $\underline{\beta_{X}<\beta_{Y}}$ & All & $\underline{\beta_{X}>\beta_{Y}}$ & $\underline{\beta_{X}<\beta_{Y}}$ \\
\hline \multirow[t]{2}{*}{ RUNUP1 } & -0.732 & -1.479 & -0.221 & -0.235 & -0.172 & & & \\
\hline & {$[-7.79]$} & {$[-8.45]$} & {$[-2.91]$} & {$[-3.07]$} & {$[-2.07]$} & & & \\
\hline RUNUP2 & & & & & & $\begin{array}{l}-0.287 \\
{[-7.29]}\end{array}$ & $\begin{array}{l}-0.296 \\
{[-6.95]}\end{array}$ & $\begin{array}{l}-0.231 \\
{[-5.11]}\end{array}$ \\
\hline \multirow[t]{2}{*}{$\mathrm{A} / \mathrm{E}$} & -0.725 & -1.495 & -0.530 & -0.152 & -0.853 & -0.448 & -0.148 & -0.678 \\
\hline & {$[-1.00]$} & {$[-1.40]$} & {$[-1.09]$} & {$[-0.01]$} & {$[-2.20]$} & & & \\
\hline \multirow[t]{2}{*}{$\mathrm{B} / \mathrm{M}$} & 0.461 & 0.803 & -0.001 & 0.014 & -0.084 & 0.059 & 0.060 & 0.019 \\
\hline & {$[4.09]$} & {$[3.71]$} & {$[-0.01]$} & {$[0.12]$} & {$[-0.66]$} & {$[0.44]$} & {$[0.56]$} & {$[0.17]$} \\
\hline \multirow[t]{2}{*}{$\mathrm{D} / \mathrm{M}$} & -0.142 & -0.205 & -0.072 & -0.080 & 0.048 & -0.015 & -0.145 & 0.012 \\
\hline & {$[-3.24]$} & {$[-2.67]$} & {$[-1.51]$} & {$[-2.01]$} & {$[1.23]$} & {$[-2.36]$} & {$[-2.19]$} & [1.09] \\
\hline \multirow[t]{2}{*}{ KBKT } & -0.133 & -0.189 & -0.029 & 0.013 & -0.080 & 0.029 & 0.057 & -0.033 \\
\hline & {$[-3.56]$} & {$[-2.81]$} & {$[-0.89]$} & {$[0.34]$} & {$[-2.29]$} & {$[1.80]$} & {$[2.38]$} & {$[-1.37]$} \\
\hline \multirow[t]{2}{*}{ MKT } & 0.820 & 1.672 & 0.173 & 0.064 & 0.121 & 0.239 & 0.221 & 0.121 \\
\hline & {$[3.28]$} & {$[3.71]$} & {$[0.97]$} & {$[0.25]$} & {$[0.48]$} & {$[1.44]$} & {$[0.93]$} & {$[0.51]$} \\
\hline \multirow[t]{2}{*}{ PCACQ } & 0.270 & 0.321 & 0.252 & 0.284 & 0.261 & 0.086 & 0.159 & 0.140 \\
\hline & [1.95] & [1.39] & {$[2.01]$} & [1.99] & [2.09] & {$[1.46]$} & [1.47] & [1.51] \\
\hline \multirow[t]{2}{*}{ RISK } & -0.067 & -0.128 & -0.358 & -0.403 & -0.268 & -0.250 & -0.300 & -0.206 \\
\hline & {$[-2.11]$} & {$[-2.24]$} & {$[-9.63]$} & {$[-7.12]$} & {$[-4.04]$} & {$[-7.43]$} & {$[-5.30]$} & {$[-3.14]$} \\
\hline \multirow[t]{2}{*}{ SIZE } & 0.024 & 0.054 & -0.037 & -0.066 & -0.011 & -0.037 & -0.069 & -0.012 \\
\hline & {$[0.97]$} & {$[1.18]$} & {$[-2.03]$} & {$[-2.53]$} & {$[-0.44]$} & {$[-2.07]$} & {$[-2.81]$} & {$[-0.50]$} \\
\hline \multirow[t]{2}{*}{ CONST } & -0.937 & -1.682 & 0.012 & 0.126 & 0.060 & 0.137 & 0.341 & 0.106 \\
\hline & {$[-1.79]$} & {$[-2.02]$} & {$[0.05]$} & {$[0.51]$} & {$[0.27]$} & {$[0.84]$} & {$[1.53]$} & {$[0.51]$} \\
\hline $\mathrm{N}$ & 831 & 831 & 972 & 573 & 399 & 972 & 573 & 399 \\
\hline
\end{tabular}


Figure 1: Beta before the restructuring date. Figure 1 plots the beta of the shares of bidding shareholders before the takeover as a function of the drift rate and the volatility of participating firms' core business valuations, and the ratio of core business valuations when the beta of the bidder's core assets is high (left column where $\beta_{X}=1.5$ ) or low (right column where $\left.\beta_{X}=0.5\right)$ compared to beta of the target's core assets $\left(\beta_{Y}=1\right)$. In this figure, the solid line represents a deal in which there is no competition and no follow-up option. The dashed line considers a deal with competition but without follow-up options. The dotted line considers a deal with follow-up options but without competition.
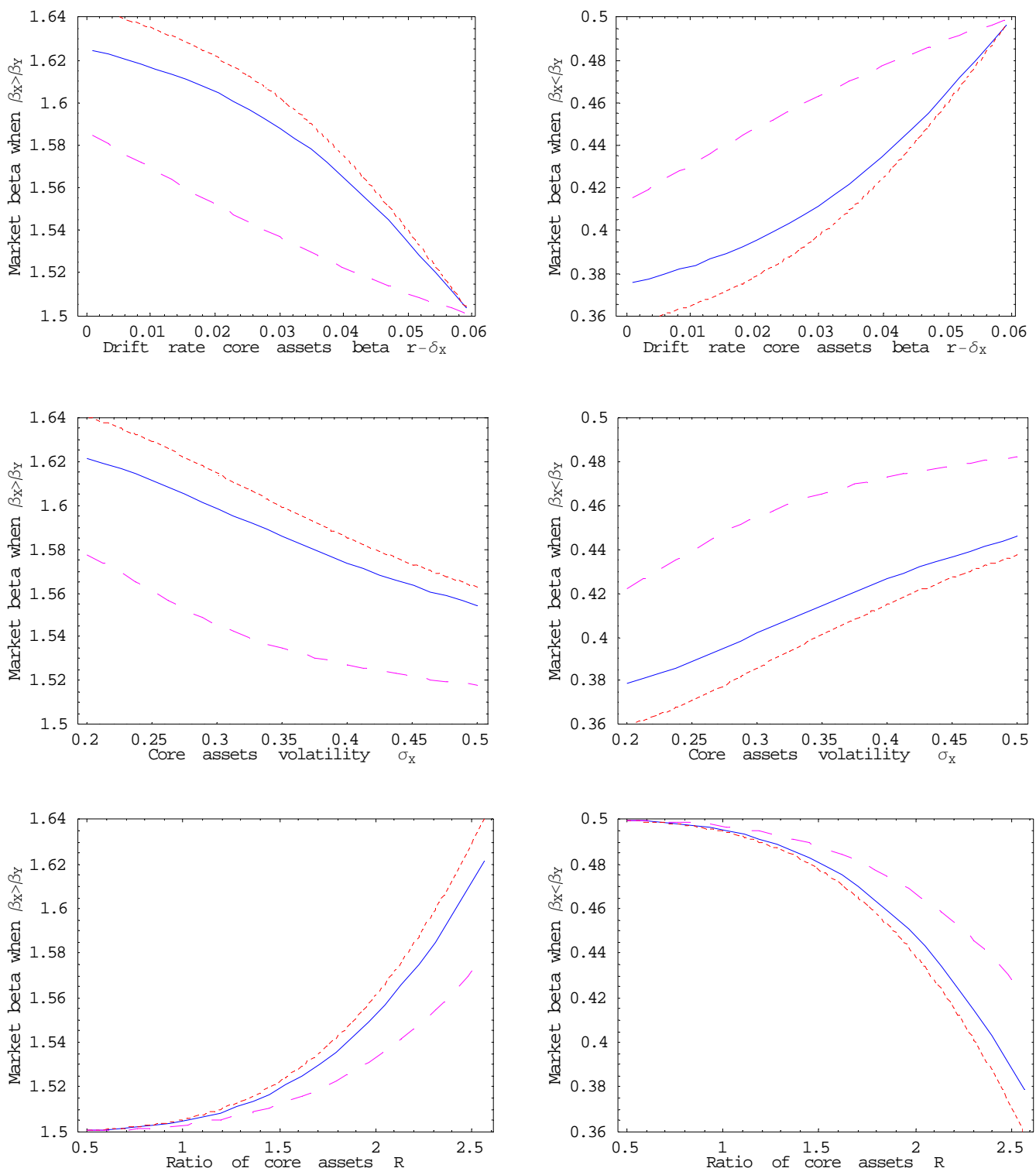
Figure 2: Change in betas at the time of the takeover. Figure 2 plots the change in the beta of the shares of bidding shareholders as a function of the relative size of the target firm $K_{B} / K_{T}$, the volatility of participating firms' core business valuations, and the correlation coefficient between these valuations when the beta of the bidder's core assets is high (left column where $\beta_{X}=1.5$ ) or low (right column where $\beta_{X}=0.5$ ) compared to the beta of the target's core assets $\left(\beta_{Y}=1\right)$. In this figure, the solid line represents a deal in which there is no competition and no follow-up option. The dashed line considers a deal with competition but without follow-up options. The dotted line considers a deal with follow-up options but without competition.
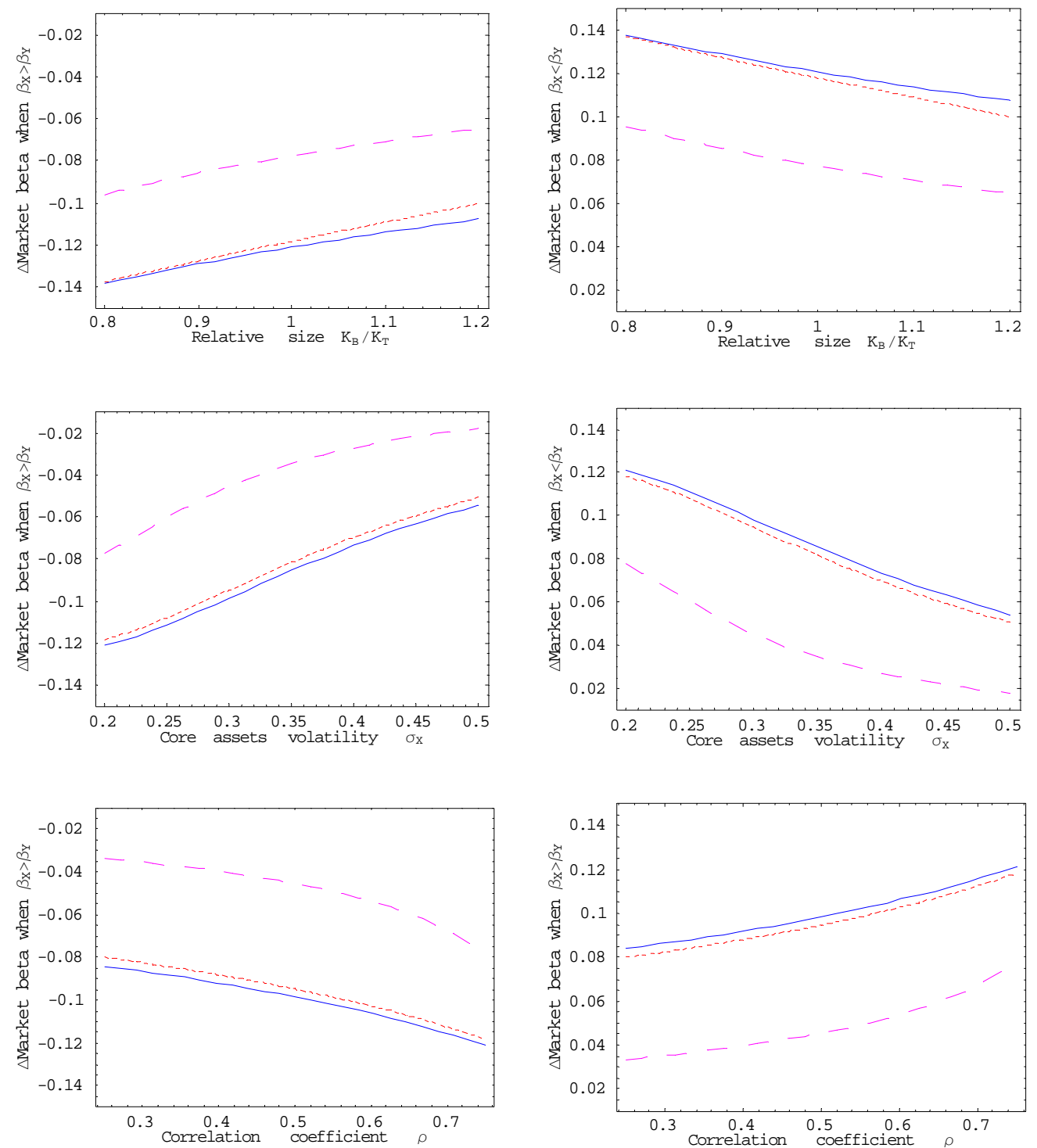
Figure 3: Risk dynamics during merger episode. Figure 3 summarizes the beta dynamics through the merger episode by plotting beta as a function of the ratio of core assets.
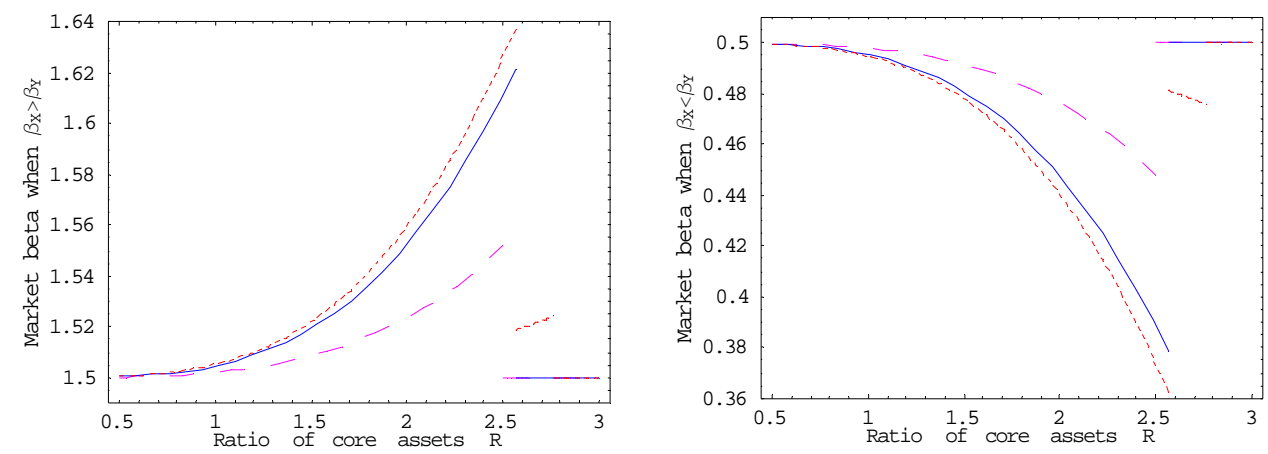

Figure 4: Change in betas at operating option exercise date. Figure 4 plots the change in the beta of the shares of bidding shareholders as a function of the option exercise price and the volatility of the participating firms' core business valuations when the beta of the bidder's core assets is higher (solid line where $\beta_{X}=1.5$ ) or lower (dashed line where $\beta_{X}=0.5$ ) than the beta of the target's core assets $\left(\beta_{Y}=1\right)$. The change in beta due to the exercise of the follow-up option is depicted either at the expansion threshold (left panels) or at the disinvestment threshold (right panels).
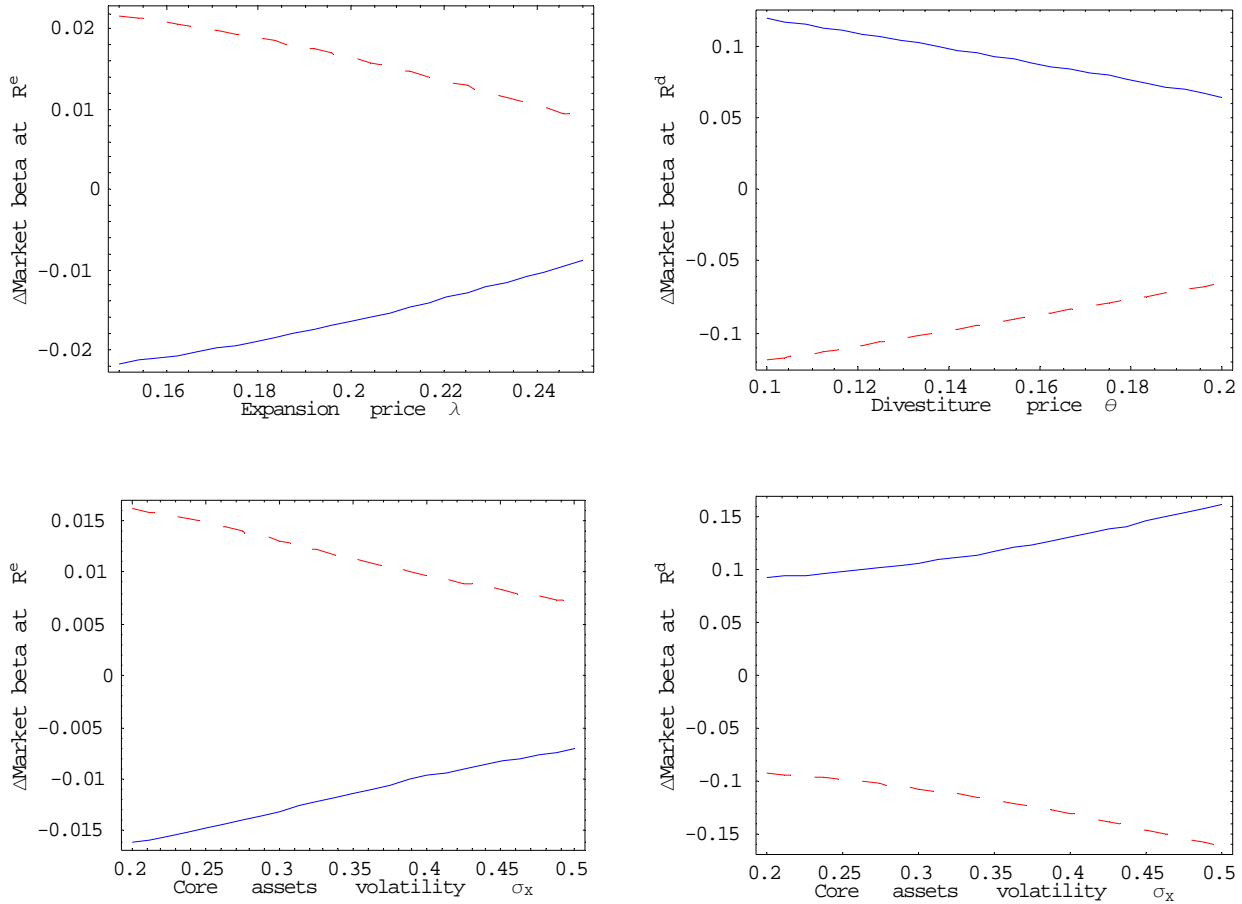
Figure 5: Announcement returns. Figure 5 plots the frequency distribution of abnormal announcement returns to the shareholders of acquiring firms and to the shareholders of targets based on our full sample of 1086 takeovers from January 1, 1985 to June 30, 2002. The event window consists of the three trading days immediately surrounding the merger announcement date; that is, from one trading day before to one trading day after the announcement day.
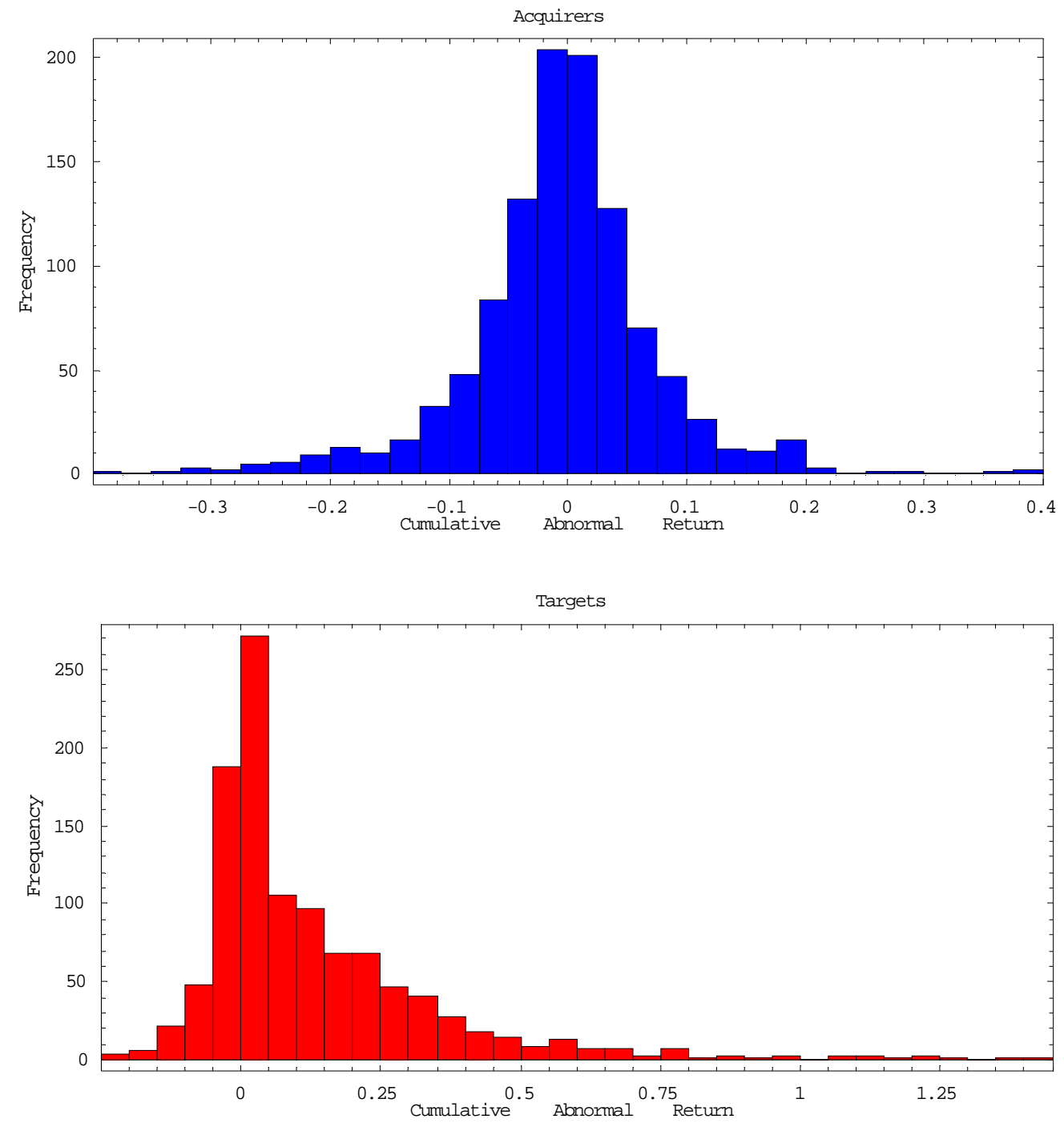
Figure 6: Beta dynamics. Figure 6a shows the dynamic pattern in acquiring firms' betas for our full sample of 1086 takeovers from January 1, 1985 to June 30, 2002. Figures 6b and $6 \mathrm{c}$ plot the beta dynamics when $\beta_{X}>\beta_{Y}$ (641 deals) and when $\beta_{X}<\beta_{Y}$ (445 deals). Every event month corresponds to 21 trading days except for event month 0 , which represents with an average of 103 trading days the time period between announcement and effective date of mergers. The dashed lines indicate the $95 \%$ confidence interval of the monthly beta estimates.
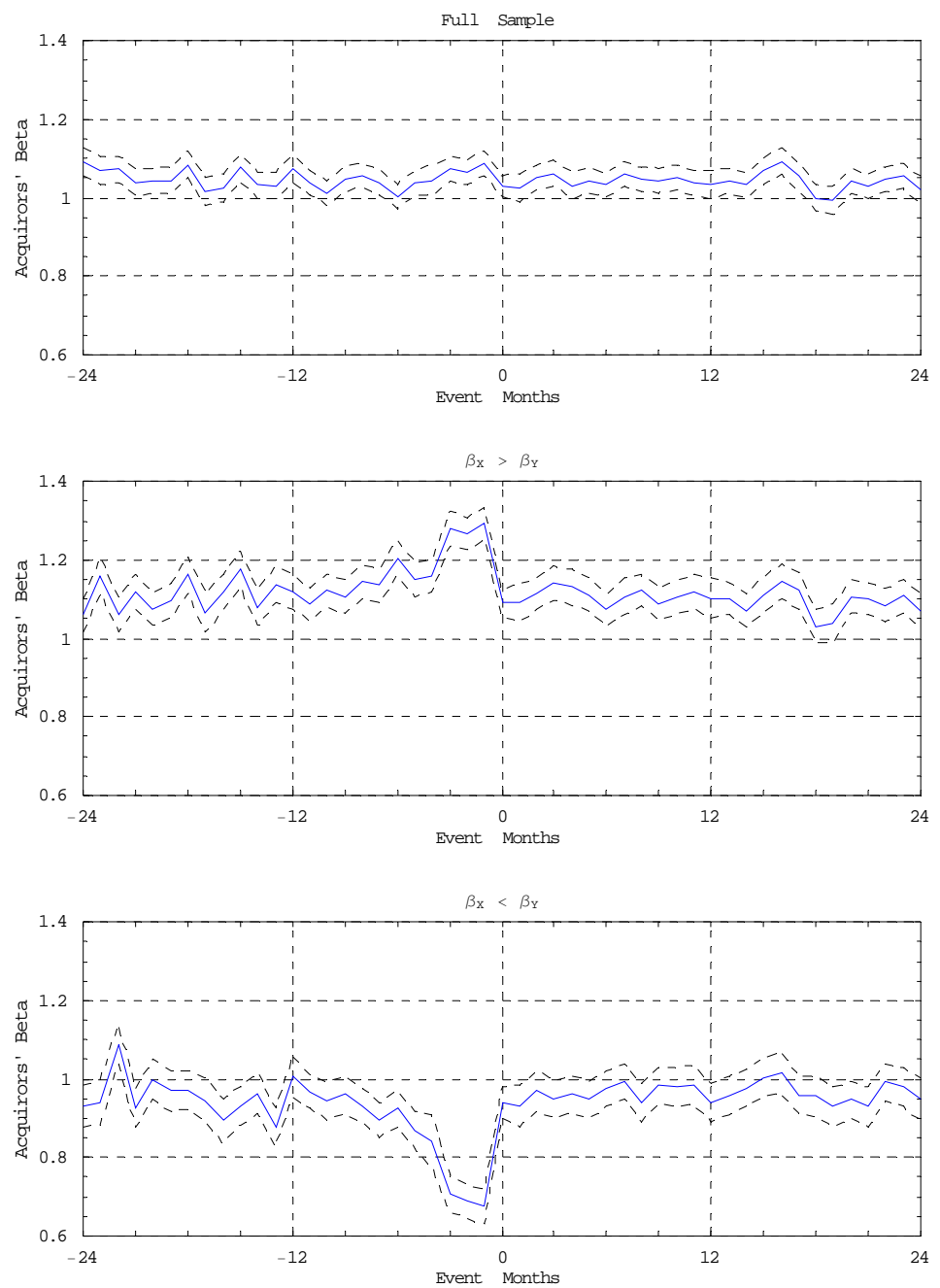
Figure 7: Beta dynamics and stock liquidity. Figure 7 shows the dynamic pattern in acquiring firms' betas depending on the pre-merger stock liquidity as measured by the Pastor and Stambaugh's (2003) gamma coefficient from the regression $r_{i t}^{e}=\theta_{i t}+\phi_{i t} r_{i t}+\gamma_{i t} \operatorname{sign}\left(r_{i t}^{e}\right)$. $v_{i t}+\epsilon_{i t}$, where $r_{i t}^{e}=r_{i t}-r_{f t}$ and $v_{i t}$ denotes daily dollar volume of stock $i$ in month $t$. Figures 7a-7c plot the acquirers' beta dynamics when $\beta_{X}>\beta_{Y}$ (634 deals) and Figures $7 \mathrm{~d}-$ $7 \mathrm{f}$ plot the acquirers' beta dynamics when $\beta_{X}<\beta_{Y}$ (437 deals). Based on 3-month preannouncement averages of $\hat{\gamma}_{i t} \mathrm{~s}$, we divide each sample into three liquidity groups of equal size. Every event month corresponds to 21 trading days except for event month 0 , which represents with an average of 103 trading days the time period between announcement and effective date of mergers. The dashed lines indicate the $95 \%$ confidence interval of the monthly beta estimates.
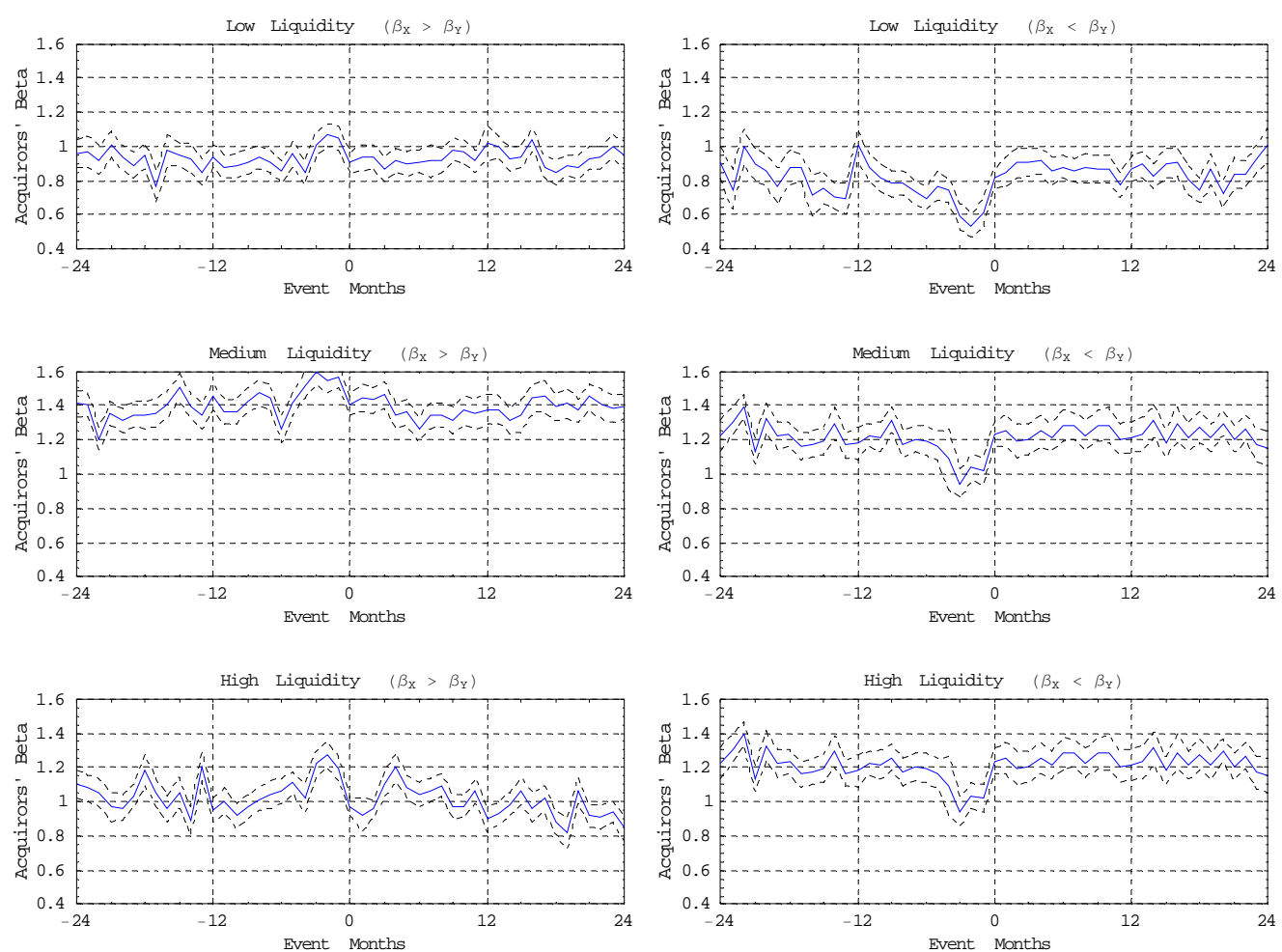
Figure 8: Beta dynamics and relative asset size. Figure 8 shows the dynamic pattern in acquirers' betas depending on the relative risk and the relative size of acquirors and targets. Relative size KBKT is defined as the ratio of acquiror's over target's total assets. Figures $8 \mathrm{a}-8 \mathrm{c}$ plot the acquirers' beta dynamics when $\beta_{X}>\beta_{Y}$ (562 deals) for subsamples below and above the median total asset ratio. Figures $8 \mathrm{~d}-8 \mathrm{f}$ plot the acquirers' beta dynamics when $\beta_{X}<\beta_{Y}$ (364 deals) for subsamples below and above the median total asset ratio. Every event month corresponds to 21 trading days except for event month 0 , which represents with an average of 103 trading days the time period between announcement and effective date of mergers. The dashed lines indicate the $95 \%$ confidence interval of the monthly beta estimates.
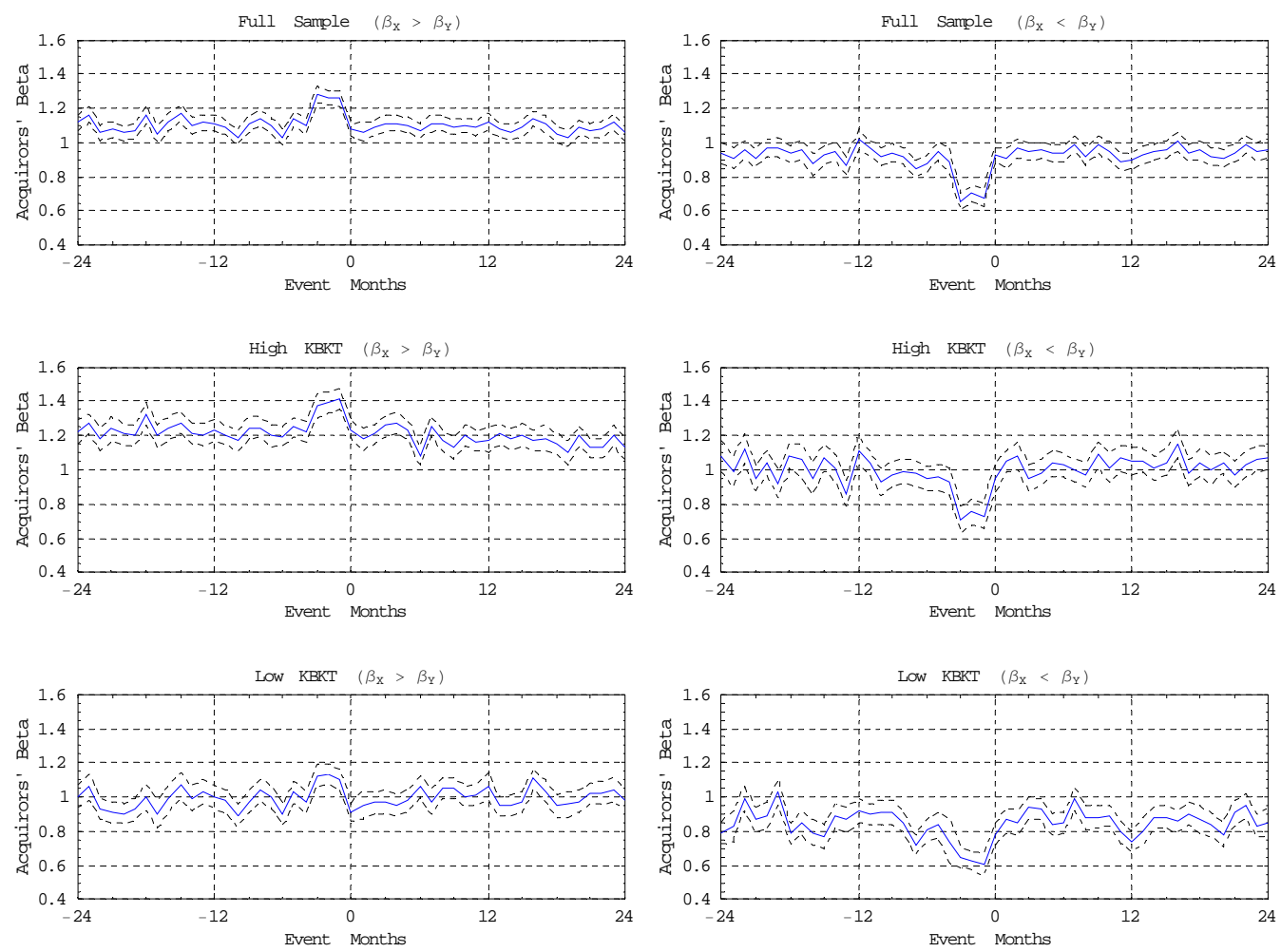